\title{
Dibujos de Duque Cornejo en el Álbum Jaffe (II): la colección del Hood Museum of Art
}

\section{Drawings by Duque Cornejo in Jaffe's Album (II): The collection at the Hood Museum of Art}

\author{
Manuel García Luque ${ }^{1}$ \\ Universidad de Sevilla
}

\begin{abstract}
Resumen: Este artículo constituye la segunda parte de un trabajo previo sobre los dibujos del escultor, pintor y arquitecto de retablos sevillano Pedro Duque Cornejo (1678-1757) que formaron parte de un álbum de dibujo desmembrado, conocido como "álbum Jaffe". En esta ocasión el estudio se ha centrado en el lote conservado en el Hood Museum of Art, Hanover (EEUU), en el cual han sido descubiertos treinta y siete nuevos dibujos atribuibles a este prolífico artista del Barroco andaluz.
\end{abstract}

Palabras clave: Dibujo, escultura barroca, Duque Cornejo, álbum Jaffe, Sevilla, siglo XVIII.

Abstract: This paper constitutes the second part of a previous study on the drawings of the Sevillian sculptor, painter and assembler Pedro Duque Cornejo (1678-1757) which were part of a scattered album, known as "Jaffe album". This study focus on the lot preserved in The Hood Museum of Art, Hanover ( $\mathrm{NH}$, USA), where thirty-seven new drawings have been discovered and attributed to this prolific artist of the Andalusian Baroque.

Key words: Drawing, Baroque sculpture, Duque Cornejo, Jaffe's album, Seville, $18^{\text {th }}$ century.

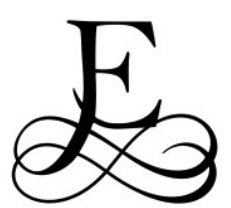

I Hood Museum of Art, actualmente integrado en el Dartmouth College, Hanover (New Hampshire, EEUU), atesora una interesante colección de dibujos españoles que fueron donados al museo en 1961 por el abogado neoyorquino William B. Jaffe. En total se trata de 101 hojas

${ }^{1}$ ORCID iD: http://orcid.org/0000-0001-9795-5679

(C) 2018 Philostrato. Revista de Historia y Arte 
procedentes de un álbum de dibujo desmembrado, modernamente conocido como "álbum Jaffe", que probablemente fue confeccionado en la Sevilla ilustrada, y que actualmente se halla repartido entre diversas colecciones estadounidenses. En un trabajo anterior tuvimos ocasión de trazar la azarosa historia de este álbum, demostrando su singularidad en el contexto de la historia del dibujo español ${ }^{2}$. En efecto, a pesar de la modesta significación de muchos de los dibujos que lo integraron, este repertorio presenta el interés de aglutinar buena parte de la obra gráfica conocida de Pedro Duque Cornejo (1678-1757), por lo que supone un raro y excepcional material para conocer los modos gráficos del artista y reconsiderar el papel que el dibujo desempeñó en el proceso creativo de una de las grandes figuras de la escultura barroca española ${ }^{3}$.

Del centenar de dibujos que se conservan en Darmouth, al menos treinta y siete pueden ser directamente atribuidos a Duque Cornejo, sin contar algunos otros de más endeble factura pero semejantes en técnica y modelos, que bien podrían pertenecer a la labor de sus aprendices en el taller ${ }^{4}$. La importancia de este conjunto resulta, pues, análoga a la treintena de dibujos ya estudiados del Metropolitan Museum of Art. Al igual que aquéllos, se trata, en su mayor parte, de estudios de figura aislada realizados a pluma, que con frecuencia presentan apariencia de rasguños o borroncillos, aunque la existencia de lápiz subyacente en muchos de ellos demuestra su carácter más meditado. En menor medida, también es posible encontrar en este lote dibujos más concluidos, realizados enteramente con el lápiz negro, o incluso bellamente sombreados con la aguada de tinta.

El interés de la colección se acrecienta al comprobar que algunos diseños resultan claramente preparatorios para esculturas, aunque conviene advertir que en ningún caso vamos a encontrar una trasposición tan literal como la ya vista entre las imágenes de San Francisco de Borja y San Estanislao de Kostka de la iglesia sevillana de San Luis y los tres estudios a pluma que conserva el Metropolitan ${ }^{5}$. Esta problemática se pone de manifiesto en los dibujos de San Joaquín y Santa Ana (Fig. 1, cat. 59 y 63), dos de los más apreciables de la colección del Hood Museum. Al menos en el caso de la santa parece evidente que se trata del estudio para una escultura, como sugiere la peana con moldura en escocia que aparece bajo sus pies. Su depurada técnica acredita el importante grado de refinamiento que Cornejo alcanzó en sus estudios más concluidos, donde el esbozo inicial a lápiz se concretó en certeros y discontinuos trazos de pluma, completados luego con un delicado sombreado

\footnotetext{
2 Manuel García Luque, "Dibujos de Duque Cornejo en el Álbum Jaffe (I): la colección del Metropolitan Museum of Art", Philostrato. Revista de Historia y Arte, 3, (2018), pp. 39-68. Tanto este artículo como el presente trabajo reelaboran materiales e ideas ya planteados en nuestra tesis doctoral Pedro Duque Cornejo: estudio de su vida y obra (1678-1757), leída en la Universidad de Granada en abril de 2018.

3 Sobre Duque Cornejo véanse las monografías de René Taylor, El entallador e imaginero sevillano Pedro Duque Cornejo (1678-1757), (Madrid: Instituto de España, 1982); y José Hernández Díaz, Pedro Duque Cornejo, (Sevilla: Diputación Provincial, 1983).

${ }^{4}$ Una interpretación de estos dibujos como producto de taller en Peter Cherry, "La formación de los pintores en los talleres sevillanos", en Zurbarán ante su centenario (1598-1998), dir. Alfonso E. Pérez Sánchez, (Valladolid: Universidad de Valladolid-Fundación Duques de Soria, 1999), pp. 49-70.

${ }^{5}$ García Luque, "Dibujos de Duque Cornejo", pp. 44-45 y cat. 19-21.
} 
de aguada grisácea. Por esta inusual finura, cabría preguntarse si el artista concibió ambos dibujos como bocetos de presentación para el cliente o simplemente estaba explorando las posibilidades expresivas de la tinta y la aguada.

Como quiera que fuese, todo hace pensar que ambos dibujos fueron realizados en la década de 1720, después de que Duque Cornejo pasara por Granada y se impregnara del gusto canesco por las formas en huso, que animan la silueta de Santa Ana6. En apoyo de esta datación, cabría recordar que fue precisamente durante su segunda etapa sevillana cuando el artista tuvo que enfrentarse en diversas ocasiones a la representación de los padres de la Virgen, cuyo culto experimentaba entonces un extraordinario auge como correlato de la creencia inmaculista. Así, además del original grupo escultórico de la parroquia de la Virgen del Rosario de Cádiz, que se le atribuye con todo fundamento ${ }^{7}$, contamos con nada menos que cuatro parejas de esculturas documentadas en estos años. Las tres primeras están realizadas en madera policromada y se encuentran repartidas entre el retablo mayor de la iglesia de la Compañía de Córdoba $(1724)^{8}$, el retablo de la Inmaculada del sagrario de la cartuja del Paular $(1727)^{9}$ y el retablo de San José en la capilla del palacio de San Telmo de Sevilla $(1728)^{10}$; la cuarta está realizada en piedra franca de Morón y forma parte del programa iconográfico del retablo de la capilla de la Virgen de la Antigua en la catedral de Sevilla $(1734-1738)^{11}$. A esta nómina habría que sumar una quinta pareja, alojada en el altar mayor de la parroquia de Nuestra Señora de la Asunción de Cantillana (Sevilla), que pese a su inferior calidad puede adscribirse a la producción del taller de Cornejo ${ }^{12}$.

\footnotetext{
${ }^{6}$ También acusa esta huella el conjunto de alegorías pétreas que decoran la fachada del palacio de San Telmo en Sevilla. Ideadas por Duque Cornejo, su ejecución material correspondió casi por entero a los oficiales Domingo Grasselli y Pedro Castillejo. Véase Teodoro Falcón Márquez, El Palacio de San Telmo, (Sevilla: Ayuntamiento, 1991), pp. 20 y 128-133.

7 Manuel García Luque, "Duque Cornejo, el último barroco", Ars Magazine: revista de arte y coleccionismo, 28, (2015), pp. 118-119.

${ }^{8}$ Aunque en ocasiones se ha dudado de su autoría, aparecen mencionadas como obras de Duque Cornejo en una crónica del XVIII, fragmentariamente publicada por Rafael Gálvez Villatoro, "Memorias de el Colegio de la Compañía de Jesús, en Córdoba, desde el año de 1553 hasta 1741", Boletín de la Real Academia de Córdoba de Ciencias, Bellas Letras y Nobles Artes, 68, (1952), pp. 257-276; Su autoría fue reivindicada por Ángel Aroca Lara, "La obra de Pedro Duque Cornejo en Córdoba: su labor escultórica en los retablos de la Magdalena y la Compañía", en Conferencias de los Cursos de Verano de la Universidad de Córdoba sobre "El Barroco en Andalucía", (Córdoba: Monte de Piedad y Caja de Ahorros de Córdoba, 1986), vol. III, pp. 11-24.

${ }_{9}^{9}$ Aunque aparecen omitidas en la relación de esculturas del Paular que da Juan Agustín Ceán Bermúdez, Diccionario Histórico de los Más Ilustres Profesores de las Bellas Artes en España, tomo II, (Madrid: Imp. de la Viuda de Ibarra, 1800), p. 26, debieron ser realizadas junto al resto en la campaña de 1725-1727. 10 Documentadas por Antonio Herrera García, "Estudio histórico sobre el Real Colegio Seminario de San Telmo, de Sevilla", Archivo Hispalense, 90 (1958), p. 55.; Su datación y pago fueron concretados por Ryan A. Howard, Pedro Duque Cornejo (1678-1757), tesis doctoral inédita, Universidad de Michigan, 1975 (reproducida por University Microfilms International, 1991), pp. 70-74 y 227.

${ }_{11}$ Para el contrato véase Antonio Sancho Corbacho, Arquitectura sevillana del siglo XVIII, (Sevilla: Laboratorio de Arte de la Universidad, 1934), pp. 10-12.

12 Las esculturas se hicieron para el retablo mayor de la iglesia de San Teodomiro de Carmona (ca. 1722), pero fueron cedidas a la parroquia de Cantillana para paliar las pérdidas patrimoniales sufridas en 1936. Fernando de la Villa Nogales y Esteban Mira Caballos, "El retablo mayor de la parroquia de Nuestra Señora de la Asunción de Cantillana", Archivo Hispalense, 237, (1995), pp. 131-134.; También parecen del taller de Duque la escultura arrodillada de San Teodomiro y el relieve de la Visión de San Ignacio en la Storta, conservados in situ. Cfr. Manuel Fernández López, Historia de la ciudad de Carmona: desde los tiempos más remotos hasta el reinado de Carlos I, (Sevilla: Imp. y Lit. de Gironés y Orduña, 1886), p. 360.; José González Isidoro, "Memoria de los edificios", en Carmona. Ciudad y monumentos, ed. Antonio Calvo Laula,
} 

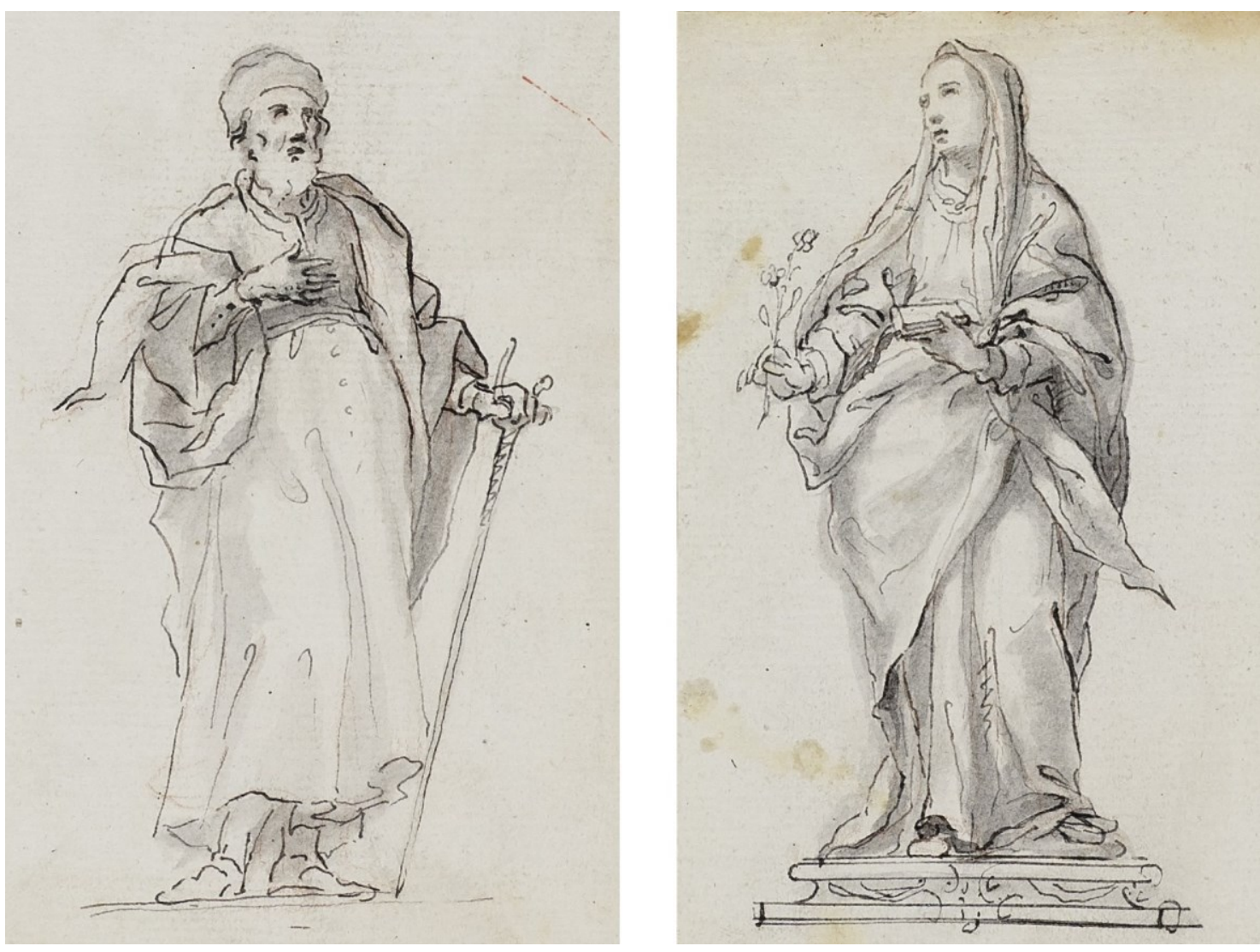

Fig. 1. Pedro Duque Cornejo, San Joaquín y Santa Ana, lápiz rojo, pluma de tinta negra y aguada grisácea sobre papel verjurado, Hanover, Dartmouth College, The Hood Museum of Art (C)

La coherencia estilística de todo este elenco resulta innegable, aunque como decíamos ninguno de los ejemplos aducidos ofrece una correspondencia directa con los dibujos del Hood Museum. Sin descartar que éstos hubieran sido realizados para una pareja de esculturas perdida o quizás nunca llevada a la práctica, es posible que el escultor fuera introduciendo sucesivos cambios durante la concreción tridimensional de las esculturas hasta el punto de que el resultado final difiera sustancialmente de la idea inicial, pues como recordaba el conde del Águila, Cornejo tenía «grande invencion, pero no la seguia, variando, haziendo y deshaziendo mientras duraba la obra» ${ }^{13}$. Teniendo en cuenta, por tanto, su peculiar método de trabajo, no sería del todo descabellado considerar estos dibujos sean estudios preparatorios para las esculturas del retablo cordobés de la Compañía, pues al margen de ligeras diferencias iconográficas -como el cordero que sostiene San Joaquín en la imagen esculpida- existe una clara correspondencia en tipos, indumentaria y composición, incluyendo algunos pormenores como el perfil ondulante que dibuja la túnica del santo en la escultura, plasmado sobre el papel en forma

Juan Fernández Lacomba, Antonio García Rodríguez y José González Isidoro, (Carmona: S \& C ediciones, 1993), p. 152.; Francisco Javier Herrera García, Fernando Quiles y Consuelo Saucedo Pradas, Carmona barroca: panorama artístico de los siglos XVII y XVIII, (Sevilla: Fundación El Monte, 1997), p. 78.

13 Juan de Mata Carriazo, "Correspondencia de don Antonio Ponz con el conde del Águila", Archivo Español de Arte y Arqueología, V, 14, (1929), pp. 180-181. 
de sinuoso arabesco.

Un problema análogo plantea el estudio para San José con el Niño (Fig. $2 a$, cat. 60), realizado con idéntica técnica de pluma y aguada, pero concebido con un carácter más fresco y espontáneo, a juzgar por el error de situar las figuras del padre y el niño a distinta altura ${ }^{14}$. La extraña alternancia de tinta sepia y parda, y los evidentes cambios de grosor en el trazo, tal vez se deban a una interrupción por falta de tinta, lo que también explicaría la concentración de aguada en algunas partes y el empleo de un sencillo plumeado de líneas paralelas para sombrear las partes restantes. La iconografía sigue el conocido modelo trentino del padre putativo guiando los primeros pasos de Jesús, tan divulgado en el mundo hispánico durante la primera mitad del siglo XVII; por una inevitable fuerza de inercia la iconografía sobrevivió también al arte de la siguiente centuria, pese a ser paulatinamente ensombrecida por la nueva modalidad que presentaba al santo carpintero sosteniendo al Niño entre pañales. El propio catálogo de Cornejo demuestra la convivencia de ambas iconografías. Al más arcaico tipo andariego pertenece el relieve que corona el retablo principal de la capilla del palacio episcopal de Córdoba (ca. 1750) ${ }^{15}$, y con anterioridad ya había tenido ocasión de afrontar el tema en dos grupos de bulto redondo, realizados con escasos años de diferencia para la hermandad de carpinteros de la localidad sevillana de Marchena (1731-1732) ${ }^{16}$ y la Casa Cuna de la capital hispalense $(1733-1734)^{17}$. Como en el caso anterior, ninguna de estas esculturas supone un calco literal del dibujo, pero no habría que descartar que el esquema planteado en esta hoja constituya, al menos, una primera idea o tanteo para el grupo de Marchena (Fig. 2b), pues tanto en el dibujo como en la escultura encontramos el peculiar detalle del canastillo sostenido por el Niño.

Otros dibujos para esculturas presentan semejante técnica de preparación a lápiz y entintado a pluma, sin llegar a ser completados con el sutil toque de aguada. Este es el caso de un curioso San Antonio de Padua (Fig. 3a, cat. 56), que ni siquiera llegó a sombrearse. Su composición trae al recuerdo la escultura de mediano formato que Duque Cornejo talló en 1725 para el retablo de San Antonio en la capilla del colegio de San Telmo de Sevilla (Fig. $3 b)$, y es posible que nos encontremos ante uno de los estudios preparatorios para esta escultura, a juzgar por la inusual forma de recoger la cogulla en la cadera, dejando a la vista la parte inferior del hábito ${ }^{18}$. De estar en lo cierto, a la hora de su concreción material el escultor mejoró la composición desde un punto de vista iconográfico, al cambiar al Niño recostado entre pañales

\footnotetext{
${ }^{14}$ Esa falta de correspondencia se advierte también en otros dibujos como la Alegoría femenina con medallón del Metropolitan; Véase García Luque, "Dibujos de Duque Cornejo", p. 54 y cat. 34.

${ }_{15}$ Atribuido por Taylor, El entallador, pp. 67-70, y documentado en Manuel García Luque, "La capilla de San José de la Casa Cuna de Sevilla: un ejemplo desaparecido del barroco hispalense", Archivo Hispalense, 300-303, (2016), pp. 424-425.

16 Manuel Antonio Ramos Suárez, "Juan del Castillo y Francisco Casaus, retablistas en la iglesia de San Juan Bautista de Marchena (Sevilla)", Laboratorio de Arte, 14, (2001), pp. 263-264.; Juan Luis Ravé Prieto, La Parroquia de San Juan Bautista de Marchena, (Marchena: Codexsa, 2006), p. 39.

17 García Luque, "La capilla de San José", pp. 409-417.

18 Fue documentado por Herrera García, "Estudio histórico", p. 55.; Su datación y pago quedaron concretados en el trabajo de Howard, Pedro Duque Cornejo, pp. 70-74 y 227.
} 


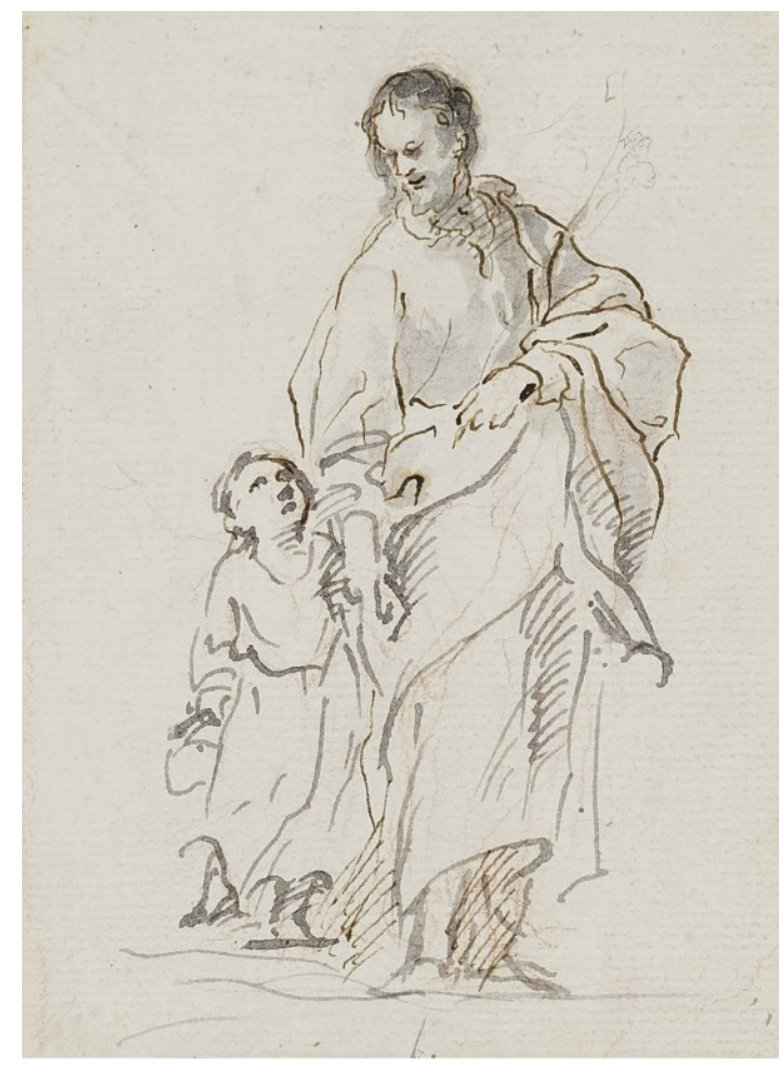

Fig. 2a. Pedro Duque Cornejo, San José con el Niño, pluma de tinta parda y sepia y aguada grisácea sobre papel verjurado, Hanover, Dartmouth College, The Hood Museum of ArtC

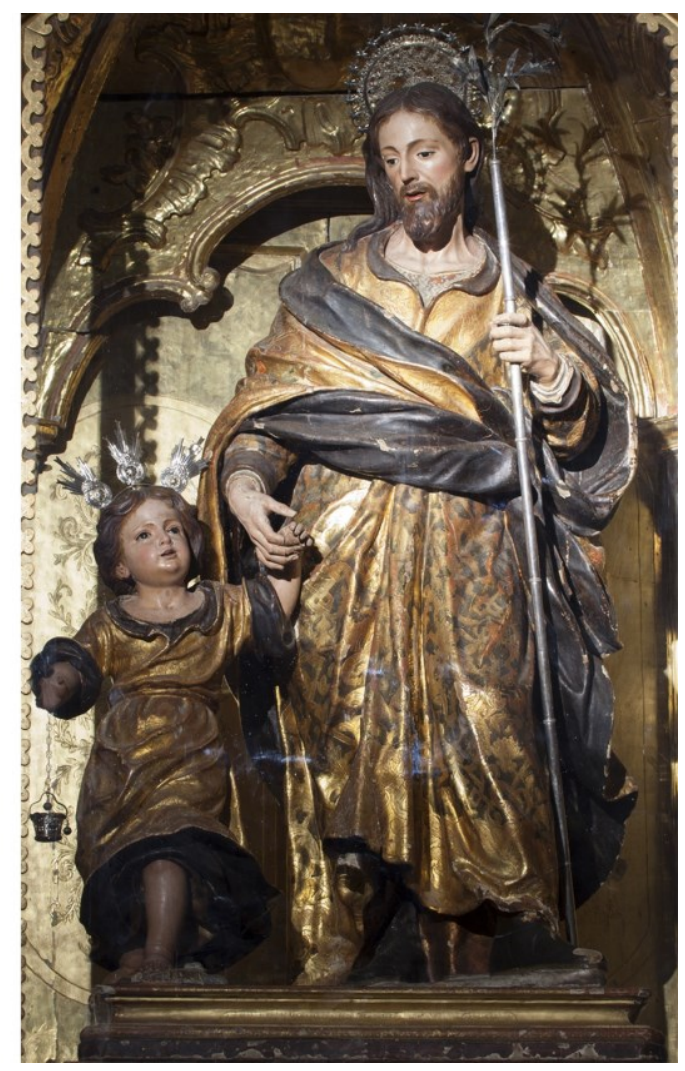

Fig. 2b. Pedro Duque Cornejo, San José con el Niño, madera policromada, 1731-1732, Marchena, parroquia de San Juan Bautista [Fotografía: autor]

por otro sentado sobre un libro, en alusión a la milagrosa visión experimentada por el santo portugués en los alrededores de Camposampiero. Este recurso del libro constituía una vuelta a la tradición, pero Cornejo no desaprovechó la oportunidad para establecer un diálogo visual entre los personajes y profundizar así en sus aspectos emocionales. Como ya vimos, este interés por la retórica de los afectos encuentra su razón de ser en el estudio de las obras de Murillo ${ }^{19}$, y se constata también en otros dibujos como la Aparición del Niño a San Antonio del Metropolitan, concebido en términos más decididamente pictóricos ${ }^{20}$.

También puede considerarse tanteo para escultura el movido apunte de Santa Bárbara (Fig. 4a, cat. 64), en el que el artista se vale del lápiz negro para marcar las líneas compositivas y matizar el volumen y la sombra. El carácter estatuario de la composición queda avalado por la clásica peana con perfil en escocia -ya vista en el dibujo de Santa Ana (Fig. 1, cat. 63) y también presente en el estudio de Apóstol del Metropolitan ${ }^{21}-$, que aquí apa-

\footnotetext{
${ }^{19}$ Manuel García Luque, "La impronta de Murillo en la escultura sevillana del siglo XVIII", en Murillo y su estela en Sevilla, Cat. exp., dir. Benito Navarrete Prieto, (Sevilla: Ayuntamiento de Sevilla-ICAS, 2017), p. 79.

${ }^{20}$ García Luque, "Dibujos de Duque Cornejo", p. 53 y cat. 15.

${ }^{21}$ García Luque, "Dibujos de Duque Cornejo", pp. 47-48 y cat. 26.
} 


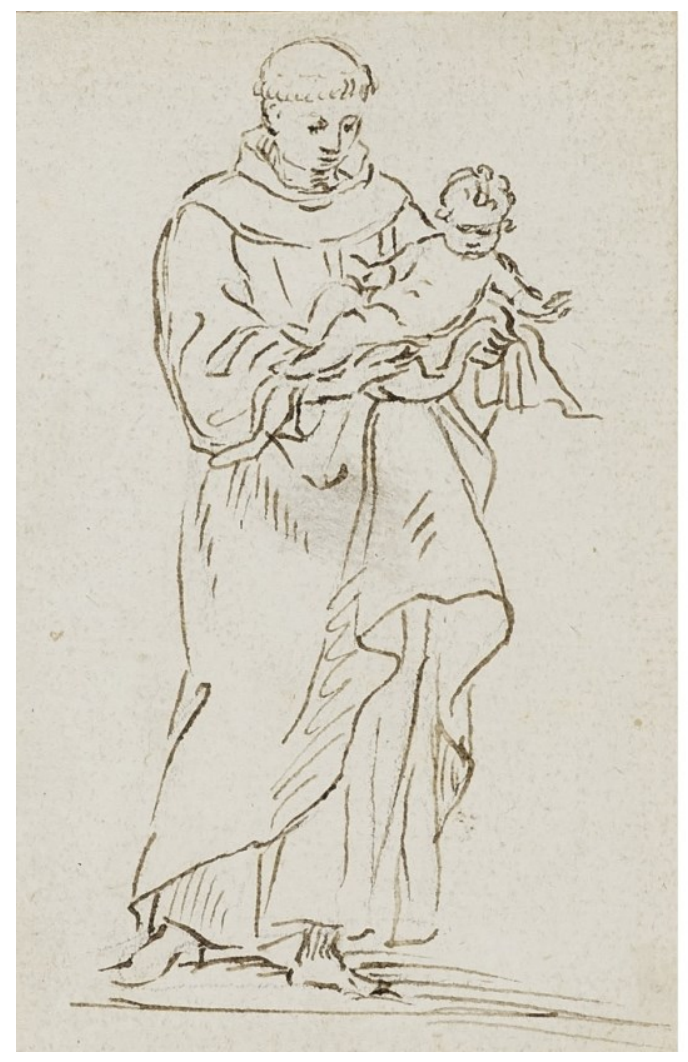

Fig. 3a. Pedro Duque Cornejo, San Antonio de Padua, lápiz negro y pluma de tinta parda sobre papel verjurado, Hanover, Dartmouth College, The Hood Museum of ArtC

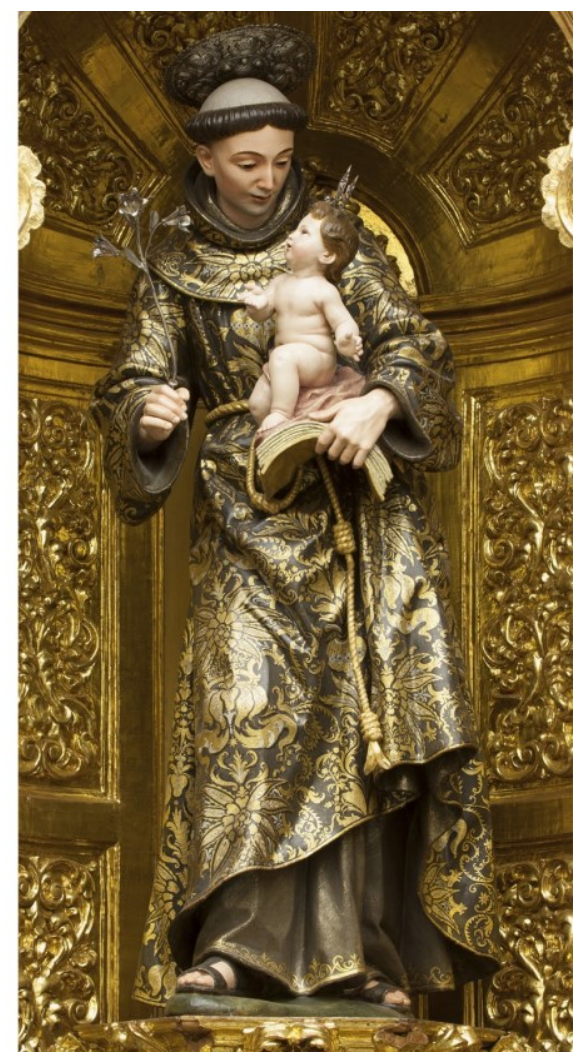

Fig. 3b. Pedro Duque Cornejo, San Antonio de Padua, madera policromada, 1725, Sevilla, capilla del palacio de San Telmo [Fotografía: autor]

rece por duplicado en un intento por contrarrestar la inestabilidad producida por el impetuoso movimiento de paños. La frescura de trazo, las proporciones estilizadas y los ritmos abiertos invitan a pensar en una cronología temprana para este dibujo, que seguramente fue realizado en un momento cercano a las pequeñas esculturas de los Evangelistas que decoran el camarín de la capilla sacramental de la parroquia de San Isidoro de Sevilla (1706-1708) ${ }^{22}$, o al San Simón de la basílica de las Angustias de Granada, que fue uno de los primeros Apóstoles en ser entregado $(1713)^{23}$.

Corrobora esta datación el hecho de que en la iglesia de San Sebastián de Marchena exista una imagen de Santa Bárbara (Fig. 4b), tallada hacia 1712, que guarda un inquietante parentesco con el dibujo. Hasta el momento, la imagen había sido considerada obra de un maestro menor llamado Juan del Castillo, quien efectivamente suscribió un contrato en agosto de este año con el párroco, y a la sazón hermano mayor de la hermandad de Santa Bárbara, para ejecutar un retablo y una escultura de la santa, que debían ser

22 Lorenzo Alonso de la Sierra Fernández y Guillermo Tovar de Teresa, "Diversas facetas de un artista de dos mundos: Gerónimo de Balbás en España y México", Atrio, 3 (1991), pp. 85-87.

23 Manuel García Luque, "Un conjunto singular del barroco sevillano en Granada: el Apostolado de la Basílica de las Angustias, obra de Pedro Duque Cornejo", Cuadernos de Arte de la Universidad de Granada, 41, (2010), p. 172. 
entregados en el plazo de un año ${ }^{24}$. A pesar de esta evidencia documental, la relación entre este dibujo de Duque Cornejo y la escultura es tan acusada que cuesta creer que todo se deba a una simple coincidencia. En efecto, con la salvedad de la palma martirial, ambas obras resultan perfectamente hermanables en ritmo y composición, y coinciden incluso en algunos pormenores como la joya en forma de medallón sobre el pecho o la torre articulada en dos cuerpos decrecientes, alusiva el cautiverio que padeció la santa.

Ante este hecho, podría pensarse que Duque Cornejo pudo suministrar algún modelo o dibujo a su colega Juan del Castillo, quien ciertamente era un viejo conocido de la familia. Su relación se remonta, al menos, a 1696, cuando colaboró con los padres de nuestro escultor en la ejecución de una Dolorosa para Carmona (la Virgen de los Dolores de la iglesia de San Bartolomé), ocupándose José Felipe Cornejo de esculpir la cabeza y manos, Francisca Roldán de encarnarlas y Juan del Castillo de realizar el candelero ${ }^{25}$. Esta colaboración se revalidaría tres años más tarde en el retablo de la capilla de la Virgen de la Soledad, en la iglesia de Santa María de la Mota de Marchena, pues Castillo contrató su ejecución con la condición de delegar el apartado escultórico en un jovencísimo Pedro Cornejo ${ }^{26}$.

Aunque no hay que descartar por completo esta hipótesis de la cesión del dibujo, las mencionadas colaboraciones arrojan una sombra de duda sobre la verdadera competencia de Juan del Castillo en trabajos de índole figurativa. Es cierto que en años sucesivos bien pudo recibir una formación específica en este campo, pero resulta más plausible que durante el resto de su trayectoria continuara valiéndose de escultores profesionales para subcontratar los encargos de talla figurativa, actuando por tanto como un intermediario entre la clientela de la campiña hispalense y los talleres de la capital. Este modus operandi podría explicar por qué algunas de las esculturas a él pagadas presentan una deuda tan acusada con la plástica de Duque Cornejo ${ }^{27}$. En el caso que nos ocupa, es posible que la Santa Bárbara fuera subcontratada con el taller de Cornejo, pero en todo caso conviene puntualizar que el maestro solo llegaría a preparar el modelo, pues su ejecución material acusa la intervención de otro escultor, acaso algún oficial de taller, algo que resulta lógico considerando que el maestro se encontraba entonces en un momento de frenética actividad, dirigiendo simultáneamente dos obradores en Sevilla y Granada28.

En este grupo de dibujos preparatorios para esculturas también merecen

\footnotetext{
24 Juan Antonio Arenillas Torrejón, "Juan del Castillo, un escultor del siglo XVIII en Marchena", Atrio, 1, 1989 , p. 83.

25 José Hernández Díaz, Antonio Sancho Corbacho y Francisco Collantes de Terán, Catálogo Arqueológico y Artístico de la Provincia de Sevilla, tomo II, (Sevilla: Diputación Provincial, 1943), p. 252.

${ }^{26}$ Arenillas Torrejón, "Juan del Castillo", pp. 81-83.

27 Semejante problemática, ofrecen la Divina Pastora de la parroquia de San Bartolomé de Carmona, cuyo retablo fue realizado por Castillo en 1709, y el San Isidro labrador de la parroquial de San Miguel de Marchena, concertado por este mismo maestro en 1711. Cfr. Hernández Díaz et al., Catálogo Arqueológico, p. 145.; Y Arenillas Torrejón, "Juan del Castillo", p. 83.

${ }_{28}$ Manuel García Luque, "Aportaciones al taller de Pedro Duque Cornejo en Granada", Anales de Historia del Arte, 23, Extra 1, (2013), pp. 229-241.
} 


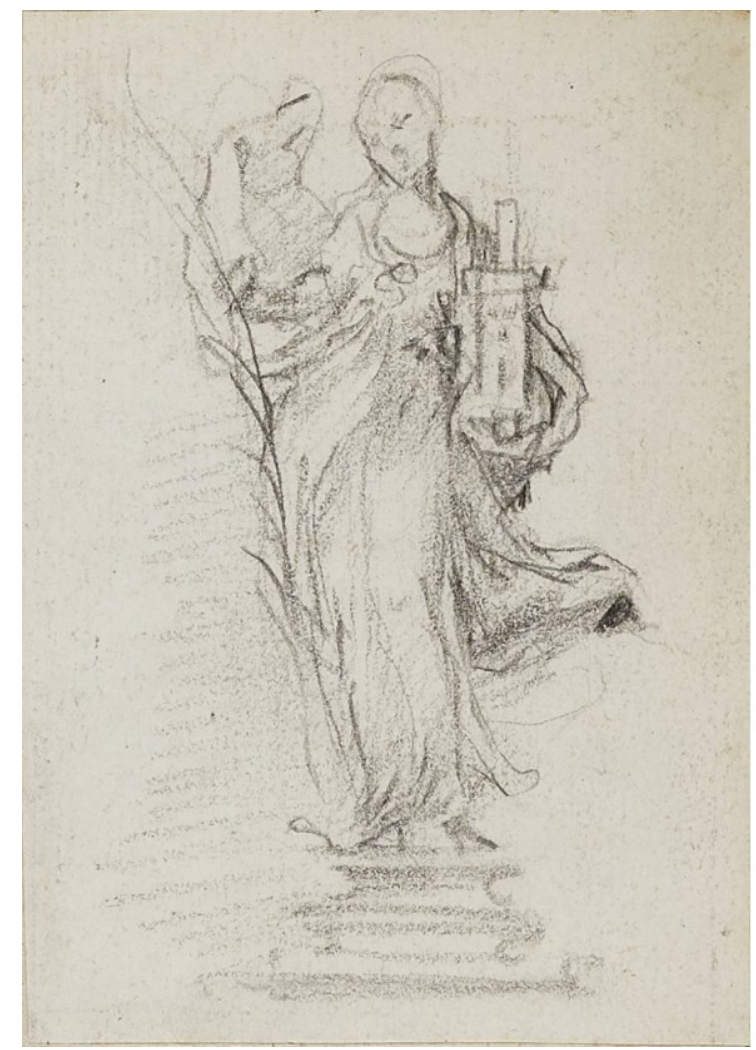

Fig. 4a. Pedro Duque Cornejo, Santa Bárbara, lápiz negro sobre papel verjurado, Hanover, Dartmouth College, The Hood Museum of Art $(\mathrm{C}$

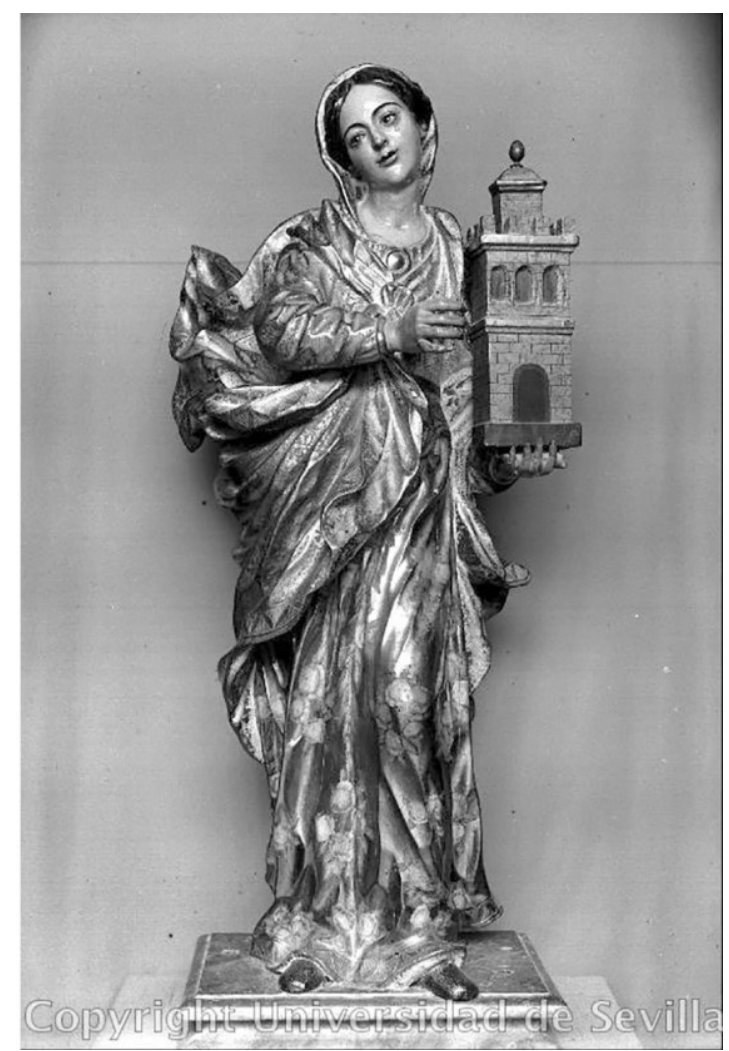

Fig. 4b. Círculo o taller de Duque Cornejo, Santa Bárbara, madera policromada, 1712-1713, Marchena, parroquia de San Sebastián [Fotografía: Fototeca del Laboratorio de Arte, Universidad de Sevilla] (C)

destacarse algunos estudios de temática concepcionista. Es probable que el más antiguo sea un dibujo a lápiz negro, que se distingue del resto por estar realizado sobre un tipo de papel grisáceo y presentar algunos realces de albayalde no vistos hasta ahora en otros dibujos del álbum Jaffe (cat. 46). A pesar de haber quedado inconcluso, se trata de un diseño de indudable interés por cuanto parece un tanteo para la pequeña escultura de la Inmaculada Concepción de la abadía del Sacromonte de Granada (ca. 17101715), cuya composición aparece aquí reproducida de forma especular ${ }^{29}$.

Más conocidos resultan otros cuatro dibujos correspondientes a dos estudios de figura completa y dos estudios parciales de rostro para el tema de la Inmaculada Concepción (cat. 44-45, 49-50). Los cuatro tienen en común el estar realizados con un mismo tipo de tinta parda, que ha sido aplicada con una gruesa pluma de caña formando un sombreado de trazos paralelos y romboidales. Su factura llamó la atención de Brown, quien los publicó en su pionera monografía sobre los dibujos de Murillo como posibles

29 Ya figura con atribución a Cornejo en José Manuel Pita Andrade, Museo del Sacro Monte, (Granada: Ministerio de Educación Nacional-Dirección General de Bellas Artes), 1964, p. 14.; Fue donada a la abadía del Sacromonte en 1725 por un devoto anónimo, atribuyéndose ya entonces a Cornejo, según expusimos en nuestro trabajo final de máster defendido en la Universidad de Granada en 2010 bajo el título Pedro Duque Cornejo en Granada, pp. 199-200. 
ejercicios de algún pintor anónimo que asistiera a las sesiones de la academia hispalense entre 1660 y $1674^{30}$. De manera más reciente uno de ellos ha sido atribuido a la actividad gráfica de Herrera el Mozo ${ }^{31}$. A nuestro juicio los tipos y la grafía de estos cuatro dibujos se relacionan claramente con algunos dibujos seguros de Duque Cornejo, como los ya comentados para las esculturas de la iglesia sevillana de San Luis de los Franceses. Además de estar ejecutados con un plumeado semejante, comparten con aquéllos las peanas nubosas circundadas de querubes y ángeles, quienes lógicamente aquí aparecen portando atributos lauretanos. Teniendo en cuenta estas analogías, es posible que estos ejercicios también correspondan a principios de la década de 1730, cuando Cornejo se encontraba en un momento de verdadera efervescencia creativa.

En cuanto a los modelos, el artista exploró dos alternativas distintas. Uno de los que presenta la figura completa está basado en la tradición iconográfica hispalense, pues la Inmaculada que eleva su mirada al cielo (cat. 44) está inspirada en el tipo de Inmaculada-Asunción acuñada por Murillo, sin renunciar a algunos elementos de la plástica derivada de Montañés como la capa que cae sobre los hombros. Cornejo funde ambos modelos y los actualiza introduciendo otros detalles iconográficos que estaban en boga en su época -como los pies que asoman bajo las vestiduras para pisar la serpiente apocalíptica-, e infundiendo a las vestiduras una agitación sobrenatural más a tono con la poética del XVIII. Todos estos ingredientes aparecen en la escultura en madera policromada de la Concepción que preside el retablo de la iglesia de Santiago de Cádiz, sin que por ello pueda señalarse una relación de dependencia directa ${ }^{32}$.

La otra Inmaculada de cuerpo completo (Fig. 5a, cat. 45) opta en cambio por el modelo fusiforme de Cano, rastreable incluso en el gusto por orientar la media luna con las puntas hacia abajo. Como en el caso anterior, Cornejo procede a actualizar el prototipo heredado, infundiendo un carácter más ampuloso a los paños y rompiendo la silueta cerrada con el extremo picudo del manto. Este rasgo ya lo vimos en otro estudio para Inmaculada del Metropolitan, realizado con el lápiz negro, y se puso en relación con la escultura de la Inmaculada de la ermita de San Telmo de Las Palmas ${ }^{33}$. Por lo que respecta a este dibujo del Hood Museum, no sería descartable que nos encontremos ante una primera idea para la escultura de la Inmaculada Concepción de la parroquial de Alcalá de Guadaira (Sevilla) -destruida en 1936-, que también contaba con un par de angelotes recostados a ambos lados de la nube (Fig. $5 b)^{34}$.

\footnotetext{
30 Jonathan Brown, Murillo and his drawings, (Princeton: Publications of the Art Museum, Princeton University, 1976), pp. 46-48.

31 Antonio García Baeza, La polifacética figura de Francisco Herrera Inestrosa, el Mozo, tesis doctoral inédita, Universidad de Sevilla, 2016, p. 81.

32 Emilio Gómez Piñol, "Retablos y esculturas de las iglesias jesuíticas en Andalucía: del clasicismo trentino al esplendor barroco del teatro sacro", en El arte de la Compañía de Jesús en Andalucía (1554-2004), (Córdoba: Cajasur, 2004), pp. 176-177.

33 García Luque, "Dibujos de Duque Cornejo", p. 52.

${ }^{34}$ Ya aparece atribuida a Cornejo en Manuel Serrano Ortega, Guía de los monumentos históricos y artísticos de los pueblos de la provincia de Sevilla, (Sevilla: Imp. de Francisco de P. Díaz, 1911), p. 45.
} 


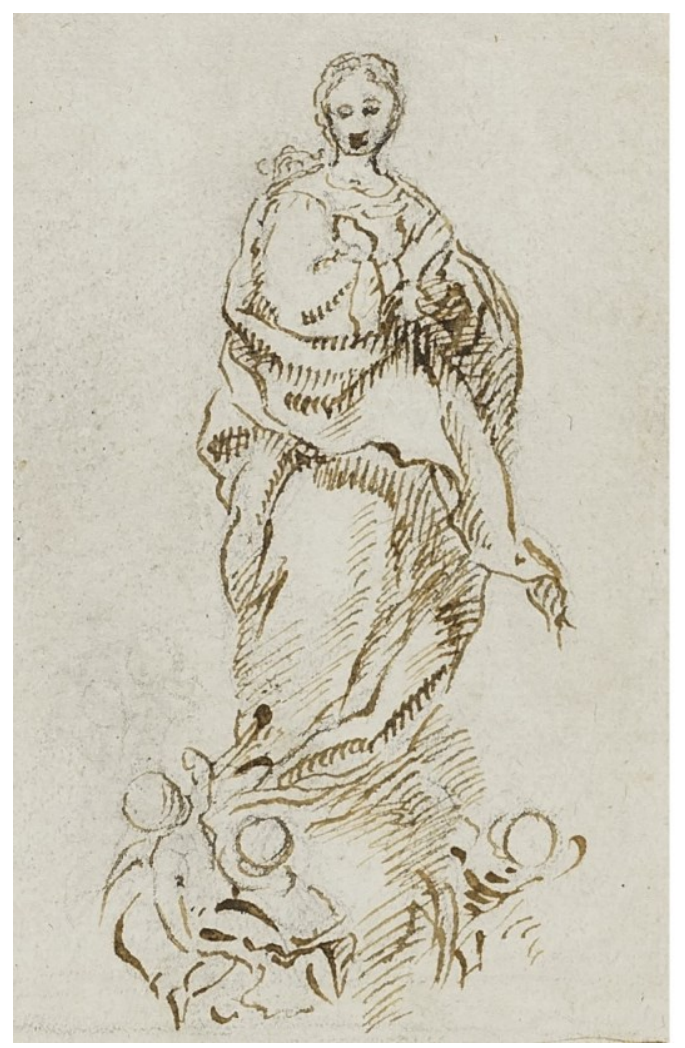

Fig. 5a. Pedro Duque Cornejo, Inmaculada Concepción, lápiz negro y pluma de tinta parda sobre papel verjurado, Hanover, Dartmouth College, The Hood Museum of Art $\mathbb{C}$

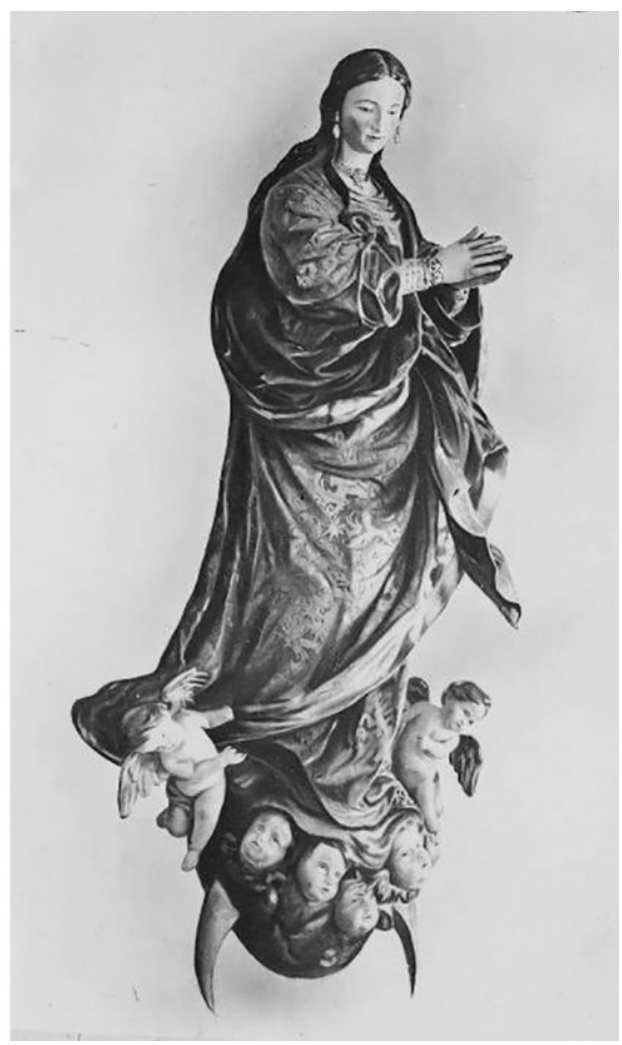

Fig. 5b. Pedro Duque Cornejo, Inmaculada Concepción, madera policromada, ca. 1730, Alcalá de Guadaira, parroquia de San Sebastián (destruida) [Fotografía: Fototeca del Laboratorio de Arte, Universidad de Sevilla]C

Esta relación de Duque Cornejo con el universo formal de Cano ha sido largamente ignorada, lo que lógicamente ha provocado que algunos de sus diseños hayan llegado a ser confundidos con la obra del maestro granadino y su extenso círculo de seguidores. Así ha ocurrido con un interesante dibujo procedente de una colección particular de Oxford y recientemente aparecido en el comercio de arte. Aunque no forma parte del álbum Jaffe, merece ser recordado aquí por su evidente relación con esta serie inmaculista (Fig. 6) ${ }^{35}$. En realidad, más que de un dibujo propiamente dicho se trata de un conjunto de ellos, realizados en una misma hoja de tamaño cercano al folio (320 x 195 $\mathrm{mm}$ ). De las tres figuras dibujadas, la que más nos interesa es la Inmaculada, realizada con una técnica mixta de lápiz, pluma y aguada, en la que se insiste en este mismo modelo fusiforme de estirpe canesca. A ambos lados aparecen dos personajes dibujados a menor escala como espontáneos rasguños de pluma. Representan a un ángel mancebo y a un soldado que hinca la rodilla en el suelo, que por el armiño y el orbe puede identificarse con San Fernando. Esta circunstancia apuntaría a que el dibujo fue realizado ya en Sevilla, en

${ }^{35}$ Fecit II: Spanish Old Master \& Modern Drawings, Cat. Exp., com. José de la Mano, (Madrid: Galería José de la Mano, 2010), pp. 17-20, cat. 4.; Debo el conocimiento de este dibujo a la gentileza de Roberto Alonso Moral, y agradezco a José de la Mano las facilidades dadas para su estudio. La hoja cuenta con una inscripción antigua tachada con aguada, en la que de forma apócrifa se añadió el nombre de Alonso Cano. 


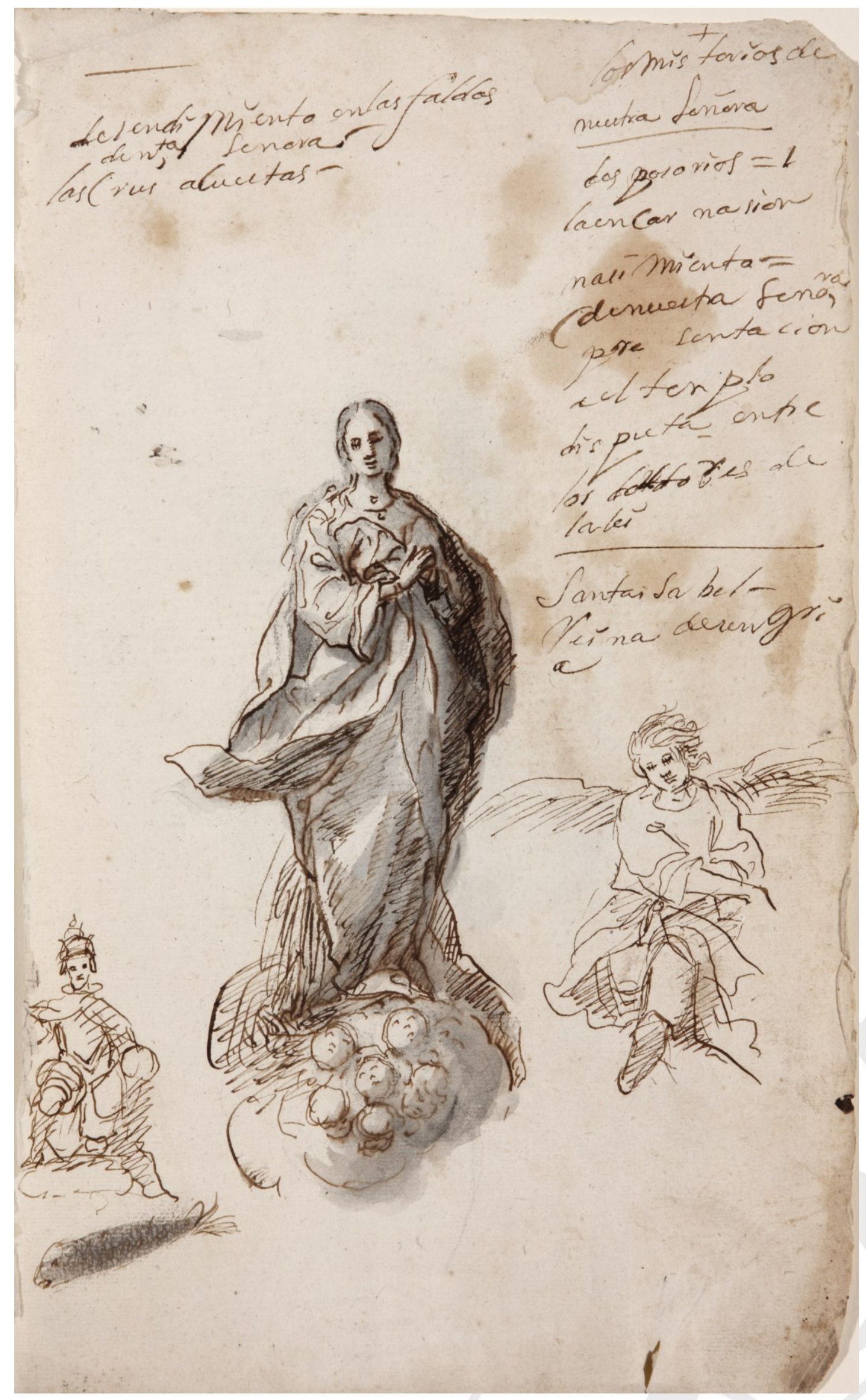

Fig. 6. Pedro Duque Cornejo, Inmaculada, San Fernando y ángel sentado, lápiz negro, pluma de tinta parda y aguada grisácea sobre papel verjurado, comercio de arte, Madrid 
algún momento de las décadas de 1720 o 1730. La hoja presenta además el interés de combinar texto e imagen, pues el artista se valió de la misma pluma para apuntar una serie de temas iconográficos ${ }^{36}$. Este aprovechamiento del espacio del papel, que se constituye en un auténtico hervidero de ideas, nos ofrece un interesante testimonio de cómo debieron ser muchos de los dibujos del álbum Jaffe antes de ser recortados por su anónimo compilador. De hecho, la letra de estos apuntes manuscritos presenta una caligrafía idéntica a la que podemos encontrar en un par de cartas autógrafas del artista conservadas en el Archivo Histórico Diocesano de Huelva, lo que no viene sino a reforzar la atribución de esta hoja37.

Por cuestiones de técnica y estilo son muchos más los dibujos del Hood Museum que se pueden atribuir con relativa seguridad a Duque Cornejo, pero algunos presentan el inconveniente de no poder relacionarse de forma directa con lo hasta ahora conocido de su producción escultórica o pictórica. Como ya se ha comentado, es posible que algunos correspondan a proyectos o tanteos para esculturas que o bien han sido destruidas, o aún están por identificar, o sencillamente nunca fueron llevadas a la práctica. Tales incógnitas surgen por ejemplo al contemplar dos estudios para Niño pasionario (Fig. 7, cat. 40-41), esbozados con el lápiz negro y abandonados en pleno proceso de entintado. Su naturaleza escultórica vendría acreditada por las peanas en forma de nube, que con tanta frecuencia empleó Duque Cornejo en sus esculturas. El hecho de que las figuras estén dibujadas con ondulantes túnicas sugiere que los Niños iban a ser cubiertos con ropajes de talla, tal vez inspirándose en la célebre escultura de Alonso Martínez de la hermandad sacramental de San Juan de la Palma de Sevilla $(1644)^{38}$.

El estudio de un Ángel mancebo (cat. 65), pergeñado a lápiz negro y luego sombreado con un fino plumeado de tinta parda, resulta igualmente problemático. Por la posición inclinada y la postura de los brazos no es difícil adivinar que se trata del estudio para un ángel lamparero, una tipología escultórica que alcanzó un enorme desarrollo en Andalucía occidental durante el siglo XVIII y que Cornejo afrontó en varias ocasiones. Sin embargo, su cotejo con las parejas de lampareros que se le han documentado (Hospital de la Caridad de Sevilla) ${ }^{39}$, y atribuido (colegiata del Salvador de la misma

\footnotetext{
${ }^{36}$ Arriba a la izquierda: "Desendimiento en las faldas / de $n$, ta senora / la crus a cuestas", y prosigue en la columna de la derecha: "[cruz] / los misterios de nuestra Señora / desposorios / la encarnasion /

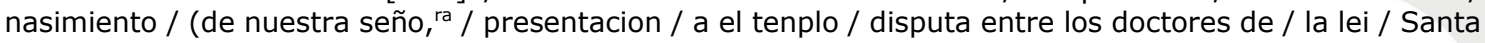
isabel- / reina de Ungri / a".

37 Datadas entre 1715 y 1716, fueron parcialmente transcritas por Manuel Carrasco Terriza, "El retablo mayor de Trigueros, obra de Miguel Franco, Duque Cornejo y Pedro Roldán (I)", Boletín Oficial del Obispado de Huelva, 254, (1985), pp. 117-124.

38 Fue policromado por Gaspar de Ribas y tradicionalmente se ha considerado obra de su hermano, el arquitecto de retablos Francisco Dionisio, a raíz de un ambiguo asiento documental en el que se declara que "la madera y hechura del Niño no costó nada porque la dio Francisco de Ribas [...] de limosna". Que Ribas la regalara no invalida que la escultura sea obra en realidad del escultor Alonso Martínez, a quien una fuente de época se lo atribuye. Cfr. María Teresa Dabrio González, Los Ribas, un taller andaluz de escultura del siglo XVII, (Córdoba: Monte de Piedad y Caja de Ahorros de Córdoba, 1985), p. 396.

39 Manuel Antonio Ramos Suárez, "Pedro Duque Cornejo y los ángeles lampararios de la Iglesia de la Santa Caridad de Sevilla", Archivo Hispalense, 276-278, (2008), pp. 259-274.
} 

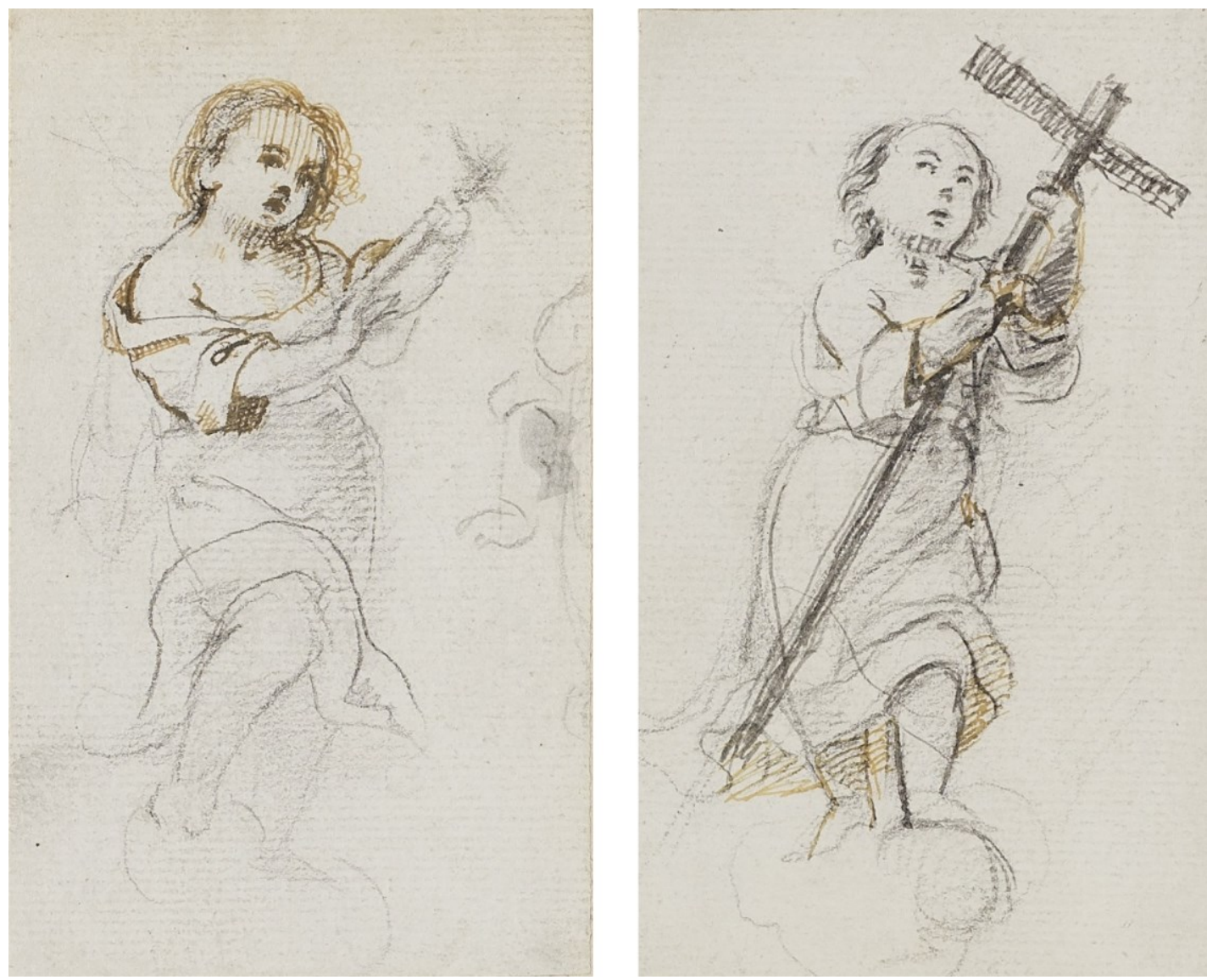

Fig. 7. Pedro Duque Cornejo, Niños pasionarios, lápiz negro y pluma de tinta parda sobre papel verjurado, Hanover, Dartmouth College, The Hood Museum of Art (C)

ciudad $)^{40}$, excluye su condición preparatoria para cualquiera de estas esculturas, a las que tan solo les une el gusto por las composiciones aspadas y los pronunciados escorzos. No obstante, hay que tener en cuenta que los ejemplos aducidos corresponden ya a la etapa de madurez, mientras que este diseño parece obra de juventud, de hacia 1700. Así lo testimonia su técnica de fino entramado romboidal, que remite a las primeras experiencias de Duque Cornejo como calcógrafo y que, en última instancia, lo emparentan con la herencia gráfica de Herrera el Viejo en Sevilla.

La existencia, tanto en el lote del Hood Museum como en la serie del Metropolitan, de varios dibujos representando a San Sebastián (cat. 62) y la Piedad (Fig. 8, cat. $42-43$ y 67) sugiere que Cornejo pudo materializar estas iconografías en escultura de bulto o relieve, pero lo cierto es que todavía no ha podido identificarse ninguna obra de esta temática entre su extensa producción. De este modo, vuelve a asaltarnos la duda sobre si tuvieron una intencionalidad práctica o simplemente fueron concebidos como simples ejercicios para adiestrarse en el manejo del lápiz y la pluma. El mismo interrogante se plantea al contemplar algunos otros dibujos como el bello Descanso en la Huida a Egipto (cat. 51) realizado con la pluma parda, o la

40 García Luque, "Duque Cornejo, el último barroco", pp. 116-117. 


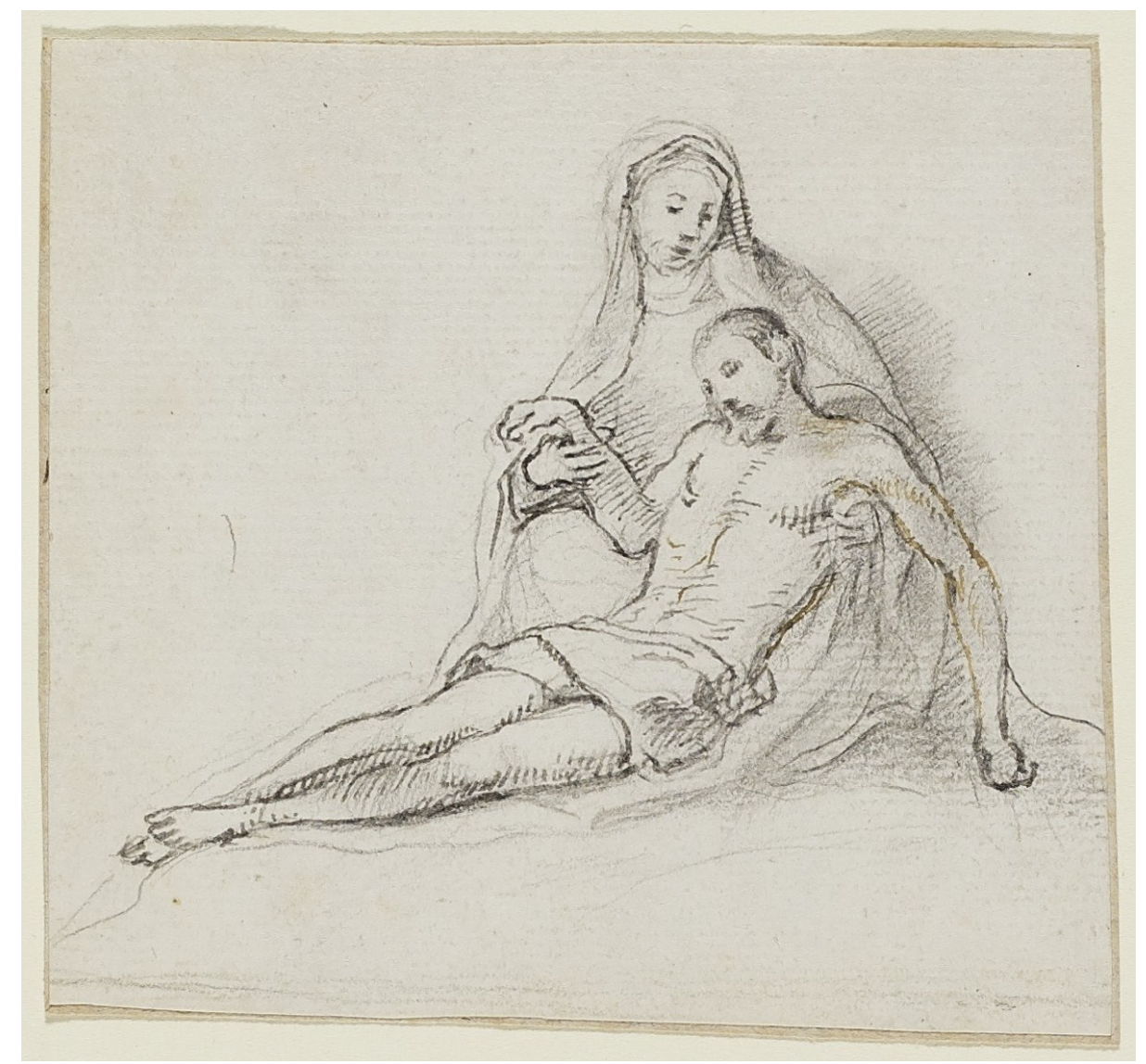

Fig. 8. Pedro Duque Cornejo, Piedad, lápiz negro y pluma de tinta negra y parda sobre papel verjurado, Hanover, Dartmouth College, The Hood Museum of Art $(\mathrm{C}$

formidable Virgen con el Niño sentada sobre una nube (Fig. 9, cat. 52), enteramente modelada con el lápiz negro. En este último, la dulce mirada que se intercambian el Niño y la madre vuelve a poner de manifiesto la pervivencia de los códigos expresivos murillescos en la obra de Duque Cornejo, ofreciendo un interesante paralelo con el ya mencionado San Antonio del palacio de San Telmo de Sevilla. La ampulosidad del manto que envuelve a la Virgen, o su toca acabada en forma de cabo suelto, forman parte del opulento lenguaje de Duque Cornejo, y resultan incluso hermanables con algunas experiencias del barroco romano. En este sentido, no dejan de resultar sorprendentes las concomitancias existentes entre este dibujo y otro perteneciente al taccuino del escultor Antonio Primo (17351798), en el que el escultor copió la Alegoría de la Inocencia pintada al fresco por Maratta en la iglesia romana de San Marco ${ }^{41}$.

No podríamos concluir esta apretada síntesis sin hacer mención de un interesante repertorio de dibujos de temática cartujana. Uno de ellos, ejecutado con la gruesa pluma de caña y destacable por la vivacidad de su

${ }^{41}$ Raquel Gallego García, "Nuevas reflexiones en torno al cuaderno de Antonio Primo (1761-1764), pensionado en Roma de la Real Academia de Bellas Artes de San Fernando de Madrid", De arte, 15, (2016), pp. 214-216. 


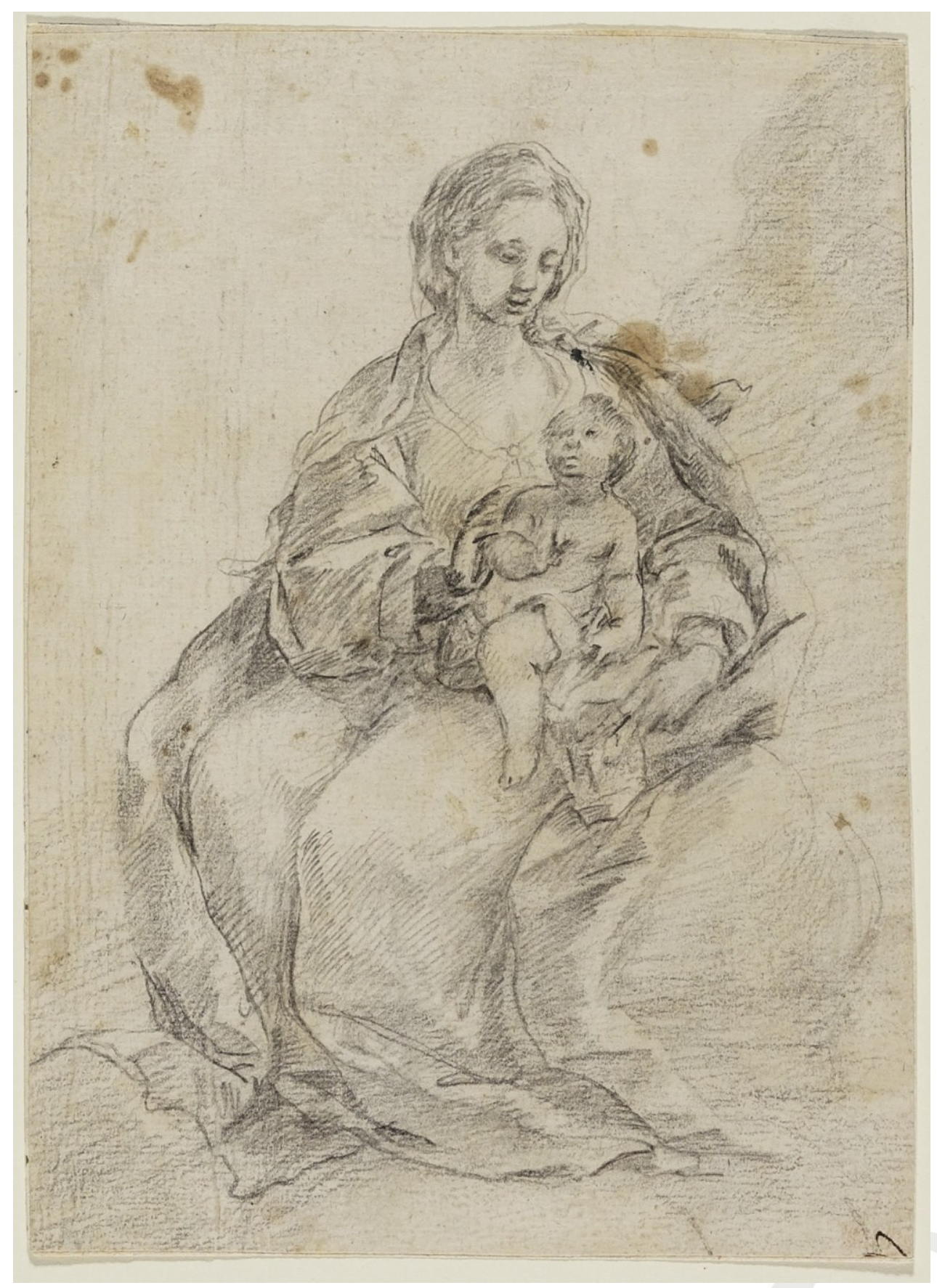

Fig. 9. Pedro Duque Cornejo, Virgen con el Niño, lápiz negro sobre papel verjurado, Hanover, Dartmouth College, The Hood Museum of Art $\mathrm{C}$

trazo, representa a un monje arrodillado ante un crucifijo y una mitra (Fig. 10, cat. 57). Se trata muy probablemente de una representación del fundador de la orden, San Bruno, quien declinó convertirse en arzobispo de la diócesis italiana de Reggio Calabria para no apartarse de la vida eremítica. Su técnica es muy cercana a la del San Francisco de Borja del Metropolitan, aunque es posible que este dibujo pertenezca ya a un periodo más tardío, cercano a 1740 , cuando el artista recibió numerosos encargos de la cartuja de Santa María de las Cuevas de Sevilla. De estas comisiones merece recordarse la serie de cinco óleos sobre lienzo representando a San Bruno y otros santos 
de la orden, que el prior Pedro de Cepas le confió con el propósito de decorar la nueva celda prioral. Aunque el ciclo se dispersó tras la desamortización, dos de estos lienzos han podido ser identificados recientemente entre los fondos del Palacio Arzobispal de Sevilla ${ }^{42}$. Se tratan de los cuadros dedicados a San Esteban de Die y San Nicolás Albergati, que al igual que este San Bruno aparecen genuflexos y virados en tres cuartos hacia el espectador, de manera que no sería de extrañar que nos encontremos ante el dibujo preparatorio de uno de los tres lienzos que todavía quedan por localizar.

El resto de dibujos de tema cartujano conforman una curiosa galería de retratos de monjes, siete en total. Su calidad es bien modesta, pero presentan un indudable atractivo considerando lo raros que resultan este tipo de testimonios gráficos en el contexto del dibujo español (Fig. 11-12, cat. 7076). Algunos están realizados con el lápiz negro, otros con la pluma parda, y alguno incluso llegó a completarse con el toque de la aguada. Pese a esta variedad de técnicas, su común escala y el sistema de representación elegido (el busto corto, visto en tres cuartos) acredita que formaron parte de una misma serie. De hecho, en algún caso es posible apreciar que se está efigiando a un mismo modelo, como se advierte en los dos apuntes a lápiz que muestran a un monje aquejado de un evidente problema de obesidad.

Por desgracia, los retratos carecen de cualquier tipo de marca o inscripción que permita identificarlos, aunque no sería descabellado que los efigiados sean algunos de los monjes que entonces habitaban la mencionada cartuja de las Cuevas. En este sentido, cabe recordar que Cornejo mantuvo una estrecha amistad con la comunidad, llegando incluso a pasar algunas temporadas de retiro en el monasterio por encontrarse "como retraído $u$ hollado de la mala fortuna"43. Fue justamente en este tiempo cuando el archivero del monasterio, el padre José Martín Rincón, estaba ultimando la redacción del Protocolo donde recogió de forma manuscrita la historia del monasterio a través de sus distintos prioratos. El libro fue convenientemente ilustrado por Duque Cornejo con una galería de retratos de los distintos priores ${ }^{44}$, por lo que parece razonable que antes de acometer semejante empresa el artista decidiera tomar algunos apuntes del natural, acudiendo lógicamente a los rostros de sus contemporáneos. La otra posibilidad pasa por considerar estos dibujos como estudios preparatorios para una obra de carácter pictórico, el Ofrecimiento de la cartuja a la Virgen de las Cuevas (49 x $61 \mathrm{~cm}$, colección particular), que acaba de incorporarse al catálogo del artista. En esta obra se advierte cierto tono retratístico en la comitiva de monjes que sostienen una curiosa maqueta del monasterio, y como ya ha quedado expuesto en otro lugar, parece que el propio artista quiso autorretratarse, asomando tímidamente entre las columnas del fondo ${ }^{45}$.

\footnotetext{
42 Manuel García Luque, "Duque Cornejo, pintor", en Barroco vivo, Barroco continuo: otras miradas sobre la creación iberoamericana, ed. Fernando Quiles y María del Pilar López, (Sevilla-Bogotá: Universidad Pablo de Olavide-Universidad Nacional de Colombia, 2018), pp. 342-343.

${ }^{43}$ Baltasar Cuartero y Huerta, Historia de la Cartuja de Santa María de las Cuevas de Sevilla y de su filial de Cazalla de la Sierra, tomo II, (Madrid: Real Academia de la Historia, 1954), pp. 171-172.

${ }_{44}$ Cuartero y Huerta, Historia de la Cartuja, tomo II, p. 171.

45 García Luque, "Duque Cornejo, pintor", pp. 343-344.
} 


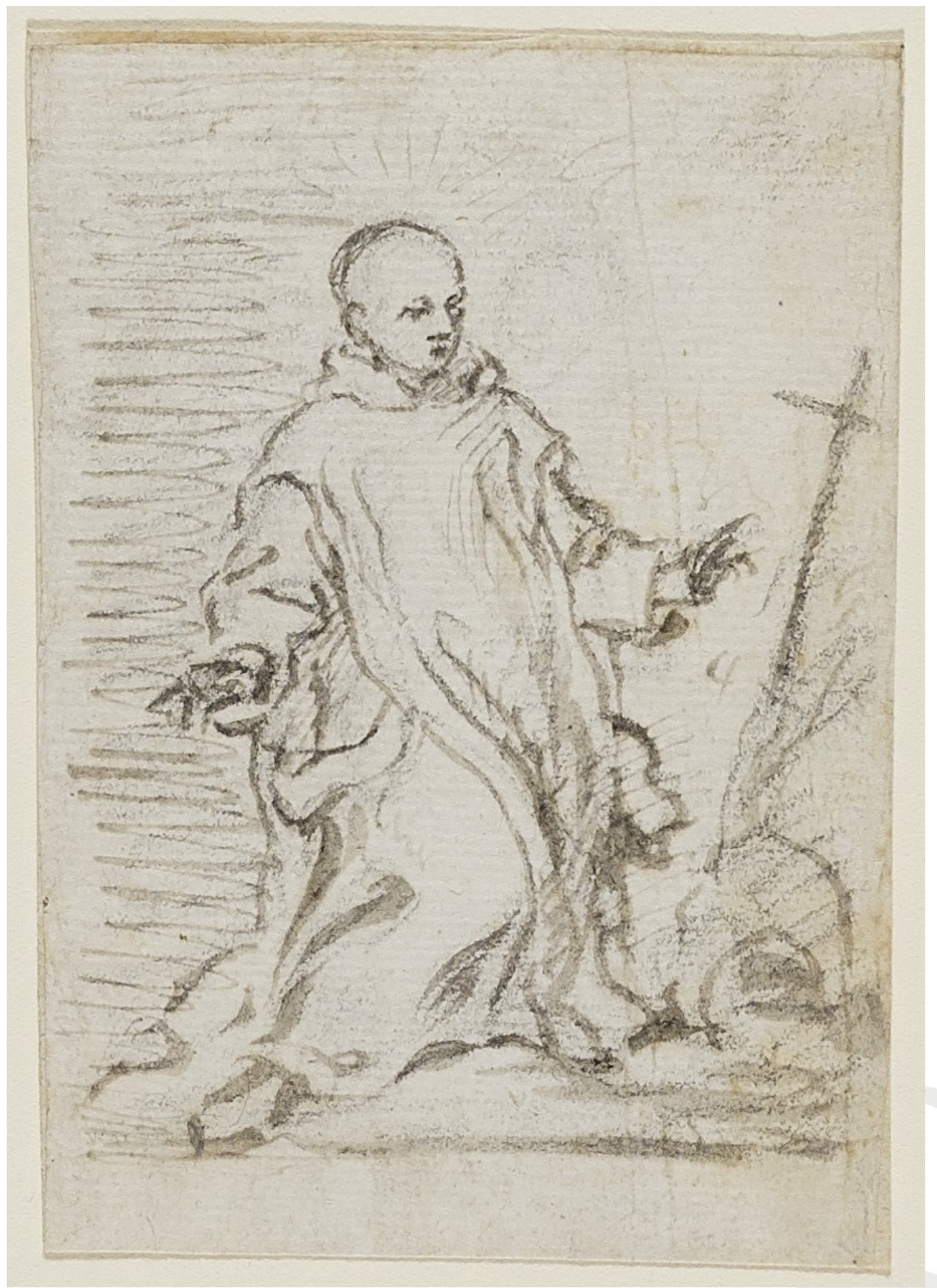

Fig. 10. Pedro Duque Cornejo, San Bruno, lápiz negro y pluma de tinta sepia sobre papel verjurado, Hanover, Dartmouth College, The Hood Museum of Art(C) 


\section{CATÁLOGO DE DIBUJOS DE DUQUE CORNEJO \\ EN THE HOOD MUSEUM OF ART ${ }^{46}$}

\section{VIDA DE CRISTO}

\section{Niño de Pasión}

Inv. no D.962.88.14

Lápiz negro y pluma de tinta parda sobre papel verjurado.

$120 \times 73 \mathrm{~mm}$.

Bibliografía: inédito.

\section{Niño de Pasión}

Inv. no D.962.88.34

Lápiz negro y pluma de tinta parda sobre papel verjurado.

$121 \times 73 \mathrm{~mm}$.

Bibliografía: inédito.

\section{Piedad}

Inv. no D.962.88.15

Lápiz negro y pluma de tinta negra y parda sobre papel verjurado.

$111 \times 140 \mathrm{~mm}$.

Bibliografía: inédito.

\section{Piedad}

Inv. no D.962.88.16b

Lápiz negro y pluma de tinta negra y parda sobre papel verjurado.

$98 \times 108 \mathrm{~mm}$.

Bibliografía: inédito.

\section{VIDA DE LA VIRGEN}

\section{Inmaculada Concepción}

Inv. no D.961.221.18a

Lápiz negro y pluma de tinta parda sobre papel verjurado.

$129 \times 69 \mathrm{~mm}$.

Bibliografía: Brown 1976, pp. 46-47, ("anonymous student of the Seville

\footnotetext{
${ }^{46}$ Los dibujos aquí reseñados han sido catalogados en nuestra tesis doctoral (véase nota 1), que va omitida en el aparato crítico de cada dibujo para evitar reiteraciones innecesarias. Por idéntica razón, en la descripción se ha evitado señalar que la mayoría de los dibujos están pegados a un segundo soporte, que corresponde a las páginas del álbum. La numeración dada continúa la del catálogo de dibujos del Metropolitan publicado en la primera parte de este trabajo.
} 
drawing academy"); Pérez Sánchez 1995, p. 42, (anónimo sevillano); García Baeza 2016, p. 81, (Herrera el Mozo).

\section{Inmaculada Concepción}

Inv. no D.961.221.18b

Lápiz negro y pluma de tinta parda sobre papel verjurado.

$120 \times 78 \mathrm{~mm}$.

Bibliografía: Brown 1976, pp. 46-47, ("anonymous student of the Seville drawing academy").

\section{Inmaculada Concepción}

Inv. no D.962.88.13b

Lápiz negro y albayalde sobre papel verjurado grisáceo.

$143 \times 79 \mathrm{~mm}$.

Bibliografía: inédito.

\section{Inmaculada Concepción}

Inv. no D.962.88.13d

Lápiz negro y pluma de tinta parda sobre papel verjurado.

$101 \times 73 \mathrm{~mm}$.

Bibliografía: inédito.

\section{Estudio para Inmaculada Concepción}

Inv. no D.962.88.18a

Lápiz negro y pluma de tinta parda sobre papel verjurado.

$90 \times 77 \mathrm{~mm}$.

Bibliografía: inédito.

\section{Estudio de cabeza de la Inmaculada Concepción}

Inv. no D.961.221.20c

Lápiz y tinta parda sobre papel verjurado.

$68 \times 49 \mathrm{~mm}$.

Bibliografía: Brown 1976, p. 48, ("anonymous student of the Seville drawing academy").

50. Estudio de cabeza de la Inmaculada Concepción

Inv. no D.961.221.20g

Lápiz y tinta parda sobre papel verjurado

$50 \times 39 \mathrm{~mm}$

Bibliografía: Brown 1976, p. 48 ("anonymous student of the Seville drawing academy")

\section{Descanso en la Huida a Egipto}

Inv. no D.961.221.17

Pluma de tinta parda sobre papel amarillento.

$152 \times 158 \mathrm{~cm}$. 
Bibliografía: Cherry 1999, p. 61, (anónimo sevillano de la segunda mitad del XVII).

\section{Virgen con el Niño}

Inv. no D.962.88.6

Lápiz negro sobre papel verjurado.

$200 \times 143 \mathrm{~mm}$.

Bibliografía: inédito.

\section{Virgen con el Niño y cabeza de anciano}

Inv. no D.962.88.33

Lápiz negro y aguada grisácea sobre papel.

$41 \times 67 \mathrm{~mm}$.

Bibliografía: inédito.

\section{Asunción}

Inv. no D.962.88.4

Lápiz negro sobre papel verjurado.

$203 \times 152 \mathrm{~mm}$.

Bibliografía: inédito.

\section{SANTOS}

\section{Magdalena penitente}

Inv. no D.962.88.2

Pluma de tinta parda sobre papel verjurado.

$120 \times 71 \mathrm{~mm}$.

Bibliografía: inédito.

\section{San Antonio con el Niño}

Inv. no D.962.88.36

Lápiz negro y pluma de tinta parda sobre papel verjurado.

$125 \times 80 \mathrm{~mm}$.

Bibliografía: inédito.

\section{San Bruno}

Inv. no D.962.88.16a

Pluma de tinta sepia sobre papel verjurado.

$105 \times 98 \mathrm{~mm}$.

Bibliografía: inédito.

\section{San Gabriel arcángel}

Inv. no D.962.88.28

Lápiz negro sobre papel verjurado.

$175 \times 187 \mathrm{~mm}$. 
Bibliografía: inédito.

\section{San Joaquín}

Inv. no D.962.88.10

Lápiz rojo, pluma de tinta negra y aguada grisácea sobre papel verjurado $133 \times 120 \mathrm{~mm}$.

Bibliografía: inédito.

\section{San José con el Niño}

Inv. no D.962.88.35

Pluma de tinta parda y sepia y aguada grisácea sobre papel.

$129 \times 96 \mathrm{~mm}$.

Bibliografía: inédito.

\section{Estudio de cabeza masculina (¿San José?)}

Inv. no D.961.221.20e

Pluma de tinta parda sobre papel verjurado.

$36 \times 30 \mathrm{~mm}$.

Bibliografía: inédito.

\section{San Sebastián}

Inv. no D.962.88.29

Lápiz negro y pluma de tinta parda sobre papel verjurado.

$197 \times 111 \mathrm{~mm}$.

Bibliografía: inédito.

\section{Santa Ana}

Inv. no D.962.88.13c

Lápiz rojo, pluma de tinta negra y aguada grisácea sobre papel verjurado $120 \times 76 \mathrm{~mm}$.

Bibliografía: inédito.

\section{Santa Bárbara}

Inv. no D.962.88.31b

Lápiz negro sobre papel verjurado.

$108 \times 76 \mathrm{~mm}$.

Bibliografía: inédito.

\section{ÁNGELES Y MISCELÁNEA}

\section{5. Ángel mancebo lamparero}

Inv. no D.962.88.9

Lápiz negro y pluma de tinta parda sobre papel verjurado.

$171 \times 167 \mathrm{~mm}$.

Bibliografía: Lawrence 1974, pp. 65-68, (anónimo sevillano del XVII). 

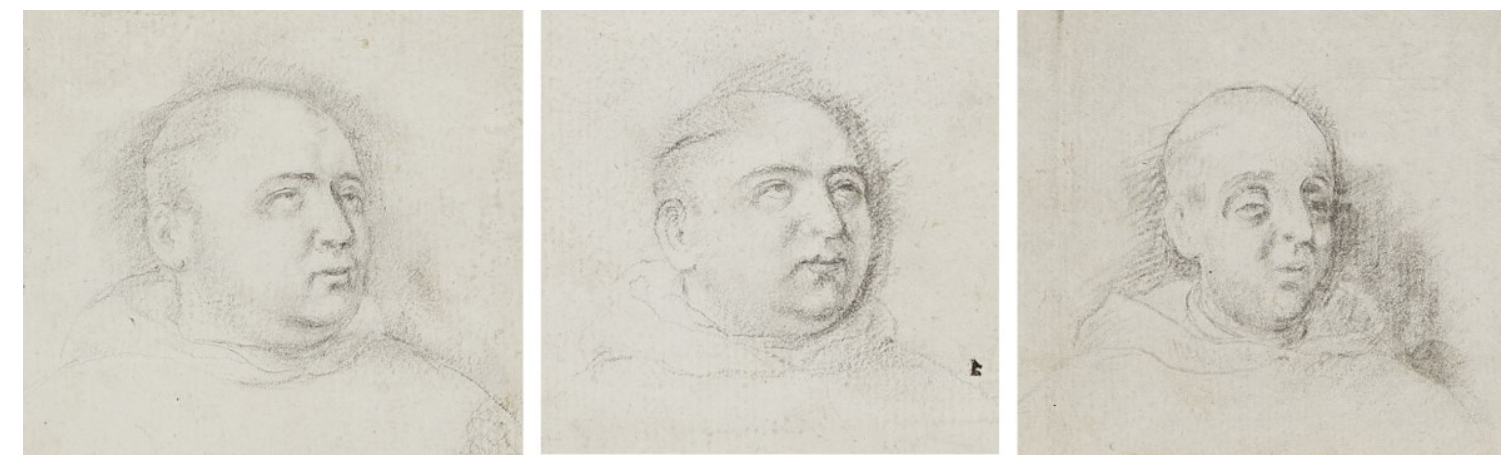

Fig. 11. Pedro Duque Cornejo, Retratos de monjes cartujos, lápiz negro sobre papel verjurado, Hanover, Dartmouth College, The Hood Museum of Art $\mathrm{C}$

66. Dos ángeles niños llorosos

Inv. no D.961.221.25d

Pluma de tinta parda sobre papel verjurado.

$66 \times 60 \mathrm{~mm}$.

Bibliografía: inédito.

\section{Caridad (recto) y Piedad (verso)}

Inv. no D.961.221.13

Pluma de tinta parda sobre papel verjurado.

$201 \times 141 \mathrm{~cm}$.

Bibliografía: inédito.

\section{Figura apoyada}

Inv. no D.962.88.18b

Pluma de tinta parda sobre papel verjurado.

$98 \times 73 \mathrm{~mm}$.

Bibliografía: inédito.

\section{ACADEMIAS Y ESTUDIOS DEL NATURAL}

\section{Muchacho tumbado}

Inv. no D.961.221.19

Pluma de tinta parda y aguada grisácea sobre papel verjurado.

$149 \times 143 \mathrm{~mm}$.

Bibliografía: inédito.

\section{Retrato de monje cartujo}

Inv. no D.962.88.21a

Lápiz negro sobre papel verjurado.

$86 \times 78 \mathrm{~mm}$.

Bibliografía: inédito. 

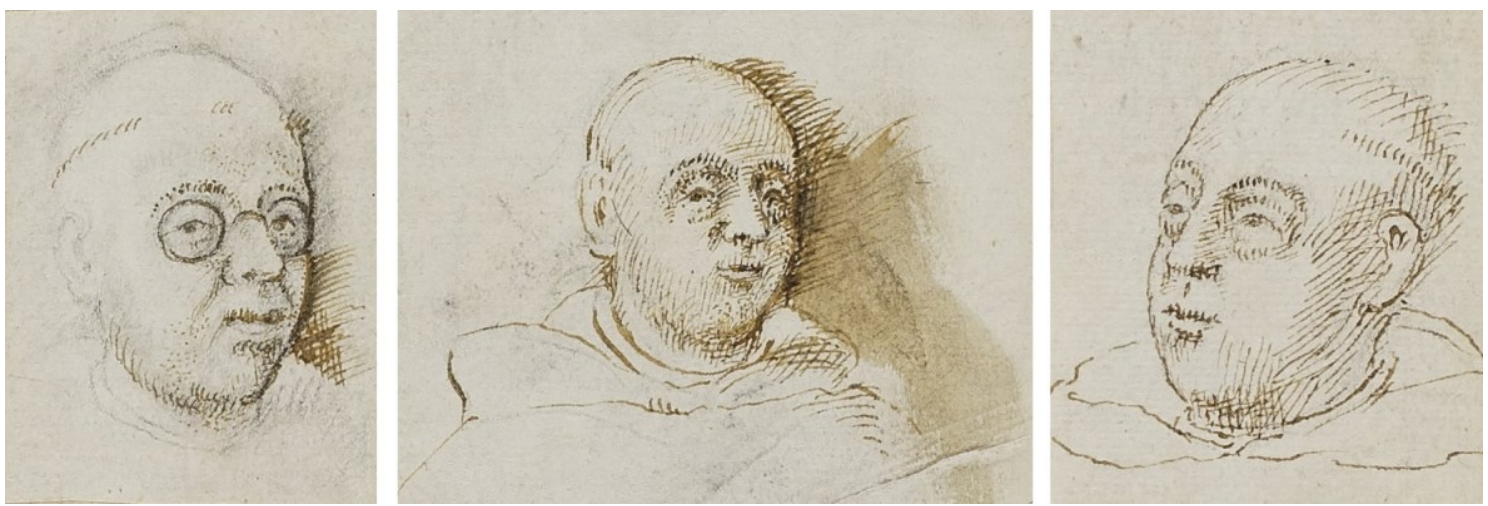

Fig. 12. Pedro Duque Cornejo, Retratos de monjes cartujos, lápiz negro, pluma y aguada de tinta parda sobre papel verjurado, Hanover, Dartmouth College, The Hood Museum of Art@

71. Retrato de monje cartujo

Inv. no D.962.88.32a

Lápiz negro sobre papel verjurado.

$65 \times 65 \mathrm{~mm}$.

Bibliografía: inédito.

72. Retrato de monje cartujo

Inv. $\mathrm{n}^{\circ} \mathrm{D} \cdot \mathbf{9 6 2 . 8 8 . 2 1 \mathrm { b }}$

Lápiz negro sobre papel verjurado.

$75 \times 83 \mathrm{~mm}$.

Bibliografía: inédito.

\section{Retrato de monje cartujo}

Inv. no D.962.88.21c

Lápiz negro y pluma de tinta parda sobre papel verjurado.

$54 \times 41 \mathrm{~mm}$.

Bibliografía: inédito.

\section{Retrato de monje cartujo}

Inv. no D.962.88.22a

Lápiz negro y pluma de tinta parda sobre papel verjurado.

$80 \times 73 \mathrm{~mm}$.

Bibliografía: inédito.

\section{Retrato de monje cartujo}

Inv. $\mathrm{n}^{\circ} \mathrm{D} .962 .88 .32 \mathrm{~b}$

Lápiz negro y tinta parda sobre papel.

$66 \times 74 \mathrm{~mm}$.

Bibliografía: inédito. 
76. Retrato de monje cartujo

Inv. no D.962.88.32c

Lápiz negro y pluma de tinta parda sobre papel.

$58 \times 46 \mathrm{~mm}$.

Bibliografía: inédito. 
Bibliografía

Alonso de la Sierra y Tovar de Teresa 1991: Lorenzo Alonso de la Sierra Fernández y Guillermo Tovar de Teresa, "Diversas facetas de un artista de dos mundos: Gerónimo de Balbás en España y México", Atrio, 3,(1991), pp. 79-107.

Arenillas Torrejón 1989: Juan Antonio Arenillas Torrejón, "Juan del Castillo, un escultor del siglo XVIII en Marchena", Atrio, 1, 1989, pp. 81-84.

Aroca Lara 1986: Ángel Aroca Lara, "La obra de Pedro Duque Cornejo en Córdoba: su labor escultórica en los retablos de la Magdalena y la Compañía", en Conferencias de los Cursos de Verano de la Universidad de Córdoba sobre "El Barroco en Andalucía", (Córdoba: Monte de Piedad y Caja de Ahorros de Córdoba, 1986), vol. III, pp. 11-24.

Brown 1976: Jonathan Brown, Murillo and his drawings, (Princeton: Publications of the Art Museum, Princeton University, 1976).

Carrasco Terriza 1985: Manuel Carrasco Terriza, "El retablo mayor de Trigueros, obra de Miguel Franco, Duque Cornejo y Pedro Roldán (I)", Boletín Oficial del Obispado de Huelva, 254, (1985), pp. 117-124.

Carriazo 1929: Juan de Mata Carriazo, "Correspondencia de don Antonio Ponz con el conde del Águila", Archivo Español de Arte y Arqueología, V, 14, (1929), pp. 157-183.

Ceán Bermúdez 1800: Juan Agustín Ceán Bermúdez, Diccionario Histórico de los Más Ilustres Profesores de las Bellas Artes en España, (Madrid: Imp. de la Viuda de Ibarra, 1800).

Cherry 1999: Peter Cherry, "La formación de los pintores en los talleres sevillanos", en Zurbarán ante su centenario (1598-1998), dir. Alfonso E. Pérez Sánchez, (Valladolid: Universidad de Valladolid-Fundación Duques de Soria, 1999), pp. 49-70.

Cuartero y Huerta 1954: Baltasar Cuartero y Huerta, Historia de la Cartuja de Santa María de las Cuevas de Sevilla y de su filial de Cazalla de la Sierra, tomo II, (Madrid: Real Academia de la Historia, 1954).

Dabrio González 1985: María Teresa Dabrio González, Los Ribas, un taller andaluz de escultura del siglo XVII, (Córdoba: Monte de Piedad y Caja de Ahorros de Córdoba, 1985).

Falcón Márquez 1991: Teodoro Falcón Márquez, El Palacio de San Telmo, (Sevilla: Ayuntamiento, 1991).

Fernández López 1886: Manuel Fernández López, Historia de la ciudad de Carmona: desde los tiempos más remotos hasta el reinado de Carlos I, (Sevilla: Imp. y Lit. de Gironés y Orduña, 1886. 
Gallego García 2016: Raquel Gallego García, "Nuevas reflexiones en torno al cuaderno de Antonio Primo (1761-1764), pensionado en Roma de la Real Academia de Bellas Artes de San Fernando de Madrid", De arte, 15, (2016), pp. 208-223.

Gálvez Villatoro 1952: Rafael Gálvez Villatoro, "Memorias de el Colegio de la Compañía de Jesús, en Córdoba, desde el año de 1553 hasta 1741", Boletín de la Real Academia de Córdoba de Ciencias, Bellas Letras y Nobles Artes, 68, (1952), pp. 257-276.

García Baeza 2016: Antonio García Baeza, La polifacética figura de Francisco Herrera Inestrosa, el Mozo, tesis doctoral inédita, Universidad de Sevilla, 2016.

García Luque 2010: Manuel García Luque, "Un conjunto singular del barroco sevillano en Granada: el Apostolado de la Basílica de las Angustias, obra de Pedro Duque Cornejo", Cuadernos de Arte de la Universidad de Granada, 41, (2010), pp. 169-188.

García Luque 2013: Manuel García Luque, "Aportaciones al taller de Pedro Duque Cornejo en Granada", Anales de Historia del Arte, 23, Extra 1, (2013), pp. 229-241.

García Luque 2015: Manuel García Luque, "Duque Cornejo, el último barroco", Ars Magazine: revista de arte y coleccionismo, 28, (2015), pp. 110121.

García Luque 2016: Manuel García Luque, "La capilla de San José de la Casa Cuna de Sevilla: un ejemplo desaparecido del barroco hispalense", Archivo Hispalense, 300-303, (2016), pp. 391-417.

García Luque 2017-2018: Manuel García Luque, Pedro Duque Cornejo: estudio de su vida y obra (1678-1757), tesis doctoral inédita, Universidad de Granada, 2017-2018.

García Luque 2017: Manuel García Luque, "La impronta de Murillo en la escultura sevillana del siglo XVIII", en Murillo y su estela en Sevilla, Cat. exp., dir. Benito Navarrete Prieto, (Sevilla: Ayuntamiento de Sevilla-ICAS, 2017), pp. 75-89.

García Luque 2018a: Manuel García Luque, "Dibujos de Duque Cornejo en el Álbum Jaffe (I): la colección del Metropolitan Museum of Art", Philostrato. Revista de Historia y Arte, 3, (2018), pp. 39-68.

García Luque 2018b: Manuel García Luque, "Duque Cornejo, pintor", en Barroco vivo, Barroco continuo: otras miradas sobre la creación iberoamericana, ed. Fernando Quiles y María del Pilar López, (Sevilla-Bogotá: Universidad Pablo de Olavide-Universidad Nacional de Colombia, 2018), pp. 330-347.

Gómez Piñol 2004: Emilio Gómez Piñol, "Retablos y esculturas de las iglesias jesuíticas en Andalucía: del clasicismo trentino al esplendor barroco del teatro 
sacro", en El arte de la Compañía de Jesús en Andalucía (1554-2004), (Córdoba: Cajasur, 2004), pp. 135-205.

González Isidoro 1993: José González Isidoro, "Memoria de los edificios", en Carmona. Ciudad y monumentos, ed. Antonio Calvo Laula, Juan Fernández Lacomba, Antonio García Rodríguez y José González Isidoro, (Carmona: S \& C ediciones, 1993), pp. 55-231.

Hernández Díaz 1983: José Hernández Díaz, Pedro Duque Cornejo, (Sevilla: Diputación Provincial, 1983).

Hernández Díaz, Sancho Corbacho y Collantes de Terán 1943: José Hernández Díaz, Antonio Sancho Corbacho y Francisco Collantes de Terán, Catálogo Arqueológico y Artístico de la Provincia de Sevilla, tomo II, (Sevilla: Diputación Provincial, 1943).

Herrera García 1958: Antonio Herrera García, "Estudio histórico sobre el Real Colegio Seminario de San Telmo, de Sevilla", Archivo Hispalense, 90, (1958), pp. 47-76.

Herrera García, Quiles y Saucedo Pradas 1997: Francisco Javier Herrera García, Fernando Quiles y Consuelo Saucedo Pradas, Carmona barroca: panorama artístico de los siglos XVII y XVIII, (Sevilla: Fundación El Monte, 1997).

Howard 1975: Ryan A. Howard, Pedro Duque Cornejo (1678-1757), tesis doctoral inédita, Universidad de Michigan, 1975 (reproducida por University Microfilms International, 1991).

Lawrence 1974: Spanish Baroque Drawings in North American Collections, Cat. Exp., dir. Gridley McKim-Smith, (Lawrence: University of Kansas, 1974).

Madrid 2010: Fecit II: Spanish Old Master \& Modern Drawings, Cat. Exp., com. José de la Mano, (Madrid: Galería José de la Mano, 2010).

Pita Andrade 1964: José Manuel Pita Andrade, Museo del Sacro Monte, (Granada: Ministerio de Educación Nacional-Dirección General de Bellas Artes), 1964.

Ramos Suárez 2001: Manuel Antonio Ramos Suárez, "Juan del Castillo y Francisco Casaus, retablistas en la iglesia de San Juan Bautista de Marchena (Sevilla)", Laboratorio de Arte, 14, (2001), pp. 259-274.

Ramos Suárez 2008: Manuel Antonio Ramos Suárez, "Pedro Duque Cornejo y los ángeles lampararios de la Iglesia de la Santa Caridad de Sevilla", Archivo Hispalense, 276-278, (2008), pp. 259-274.

Ravé Prieto 2006: Juan Luis Ravé Prieto, La Parroquia de San Juan Bautista de Marchena, (Marchena: Codexsa, 2006).

Sancho Corbacho 1934: Antonio Sancho Corbacho, Arquitectura sevillana del siglo XVIII, (Sevilla: Laboratorio de Arte de la Universidad, 1934). 
Serrano Ortega 1911: Manuel Serrano Ortega, Guía de los monumentos históricos y artísticos de los pueblos de la provincia de Sevilla, (Sevilla: Imp. de Francisco de P. Díaz, 1911).

Taylor 1982: René Taylor, El entallador e imaginero sevillano Pedro Duque Cornejo (1678-1757), (Madrid: Instituto de España, 1982).

Villa Nogales y Mira Caballos 1995: Fernando de la Villa Nogales y Esteban Mira Caballos, "El retablo mayor de la parroquia de Nuestra Señora de la Asunción de Cantillana", Archivo Hispalense, 237, (1995), pp. 131-134.

Recibido:01/10/2018

Aceptado: $29 / 11 / 2018$ 